\title{
ARTICLE Structural insight into the serotonin (5-HT) receptor family by molecular docking, molecular dynamics simulation and systems pharmacology analysis
}

\author{
Yuan-qiang Wang ${ }^{1,2,3,4,5,6}$, Wei-wei Lin $^{4,5,6}$, Nan Wu ${ }^{4,5,6}$, Si-yi Wang ${ }^{4,5,6}$, Mao-zi Chen ${ }^{4,5,6}$, Zhi-hua Lin ${ }^{1,2,3}$, Xiang-Qun Xie ${ }^{4,5,6,7}$ and \\ Zhi-wei Feng ${ }^{4,5,6}$
}

Serotonin (5-HT) receptors are proteins involved in various neurological and biological processes, such as aggression, anxiety, appetite, cognition, learning, memory, mood, sleep, and thermoregulation. They are commonly associated with drug abuse and addiction due to their importance as targets for various pharmaceutical and recreational drugs. However, due to a high sequence similarity/identity among $5-\mathrm{HT}$ receptors and the unavailability of the 3D structure of the different 5 - $\mathrm{HT}$ receptor, no report was available so far regarding the systematical comparison of the key and selective residues involved in the binding pocket, making it difficult to design subtype-selective serotonergic drugs. In this work, we first built and validated three-dimensional models for all 5$\mathrm{HT}$ receptors based on the existing crystal structures of $5-\mathrm{HT}_{1 \mathrm{~B}}, 5-\mathrm{HT}_{2 \mathrm{~B}}$, and $5-\mathrm{HT}_{2} \mathrm{C}$. Then, we performed molecular docking studies between 5-HT receptors agonists/inhibitors and our 3D models. The results from docking were consistent with the known binding affinities of each model. Sequentially, we compared the binding pose and selective residues among 5-HT receptors. Our results showed that the affinity variation could be potentially attributed to the selective residues located in the binding pockets. Moreover, we performed MD simulations for 125 -HT receptors complexed with ligands; the results were consistent with our docking results and the reported data. Finally, we carried out off-target prediction and blood-brain barrier (BBB) prediction for Captagon using our established hallucinogen-related chemogenomics knowledgebase and in-house computational tools, with the hope to provide more information regarding the use of Captagon. We showed that $5-\mathrm{HT}_{2}, 5-\mathrm{HT}_{5 \mathrm{~A}}$, and 5- $\mathrm{HT}_{7}$ were the most promising targets for Captagon before metabolism. Overall, our findings can provide insights into future drug discovery and design of medications with high specificity to the individual 5-HT receptor to decrease the risk of addiction and prevent drug abuse.

Keywords: 5-HT receptor; molecular docking; molecular dynamics simulation; systems pharmacology analysis; off-target prediction; drug abuse and addiction; drug selectivity; Captagon

Acta Pharmacologica Sinica (2019) 40:1138-1156; https://doi.org/10.1038/s41401-019-0217-9

\section{INTRODUCTION}

Serotonin or 5-hydroxytryptamine $(5-\mathrm{HT})$ is a monoamine neurotransmitter that has been linked to the regulation of mood, attention, aggression, aversive learning, impulse, and reward [1, 2]. A disrupted serotonin system can result in pathological conditions such as depression, Alzheimer's disease, schizophrenia, and migraine [3]. Serotonin exerts its effect by interacting with a complex network of receptors, which was grouped into seven subfamilies $\left(5-\mathrm{HT}_{1}-5-\mathrm{HT}_{7}\right)$ according to their structure, transduction, and function. These targets reside in the central and peripheral nervous systems (CNS/PNS), as well as a number of non-neuronal cells, such as in the gastrointestinal, blood, and endocrine systems $[1,4]$.
There are currently 14 known $5-\mathrm{HT}$ receptor subtypes. Among them, 13 receptor subtypes belong to the $G$ protein-coupled receptor (GPCR) superfamily, and $5-\mathrm{HT}_{3}$ is classified as an ion channel receptor [5-7]. 5-HT receptors can be further grouped by the $\mathrm{G}$ proteins they are coupled with. The $5-\mathrm{HT}_{1}$ and $5-\mathrm{HT}_{5}$ subtypes are coupled with $G_{i} / G_{0}$ protein, which suppresses the activity of adenylyl cyclase (AC) and decreases the level of cyclic adenosine monophosphate (CAMP). In contrast, $5-\mathrm{HT}_{4}, 5-\mathrm{HT}_{6}$, and $5-\mathrm{HT}_{7}$ increase the activity of $\mathrm{AC}$ and increase the level of cAMP by coupling with the $\mathrm{G}_{\mathrm{s}}$ protein [8]. The $5-\mathrm{HT}_{2}$ receptor couples with $\mathrm{G}_{\mathrm{q}} / \mathrm{G}_{11}$ protein, which promotes the activity of phospholipase $C$ and increases the levels of inositol trisphosphate and calcium cation $\left(\mathrm{Ca}^{2+}\right)$ [9].

\footnotetext{
${ }^{1}$ School of Pharmacy and Bioengineering, Chongqing University of Technology, Chongqing 400054, China; ${ }^{2}$ Chongqing Key Laboratory of Medicinal Chemistry and Molecular

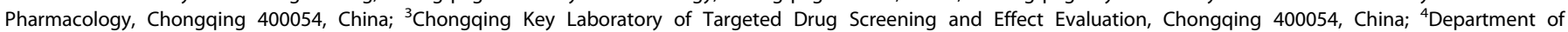

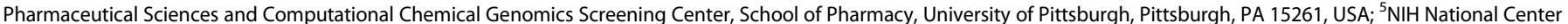

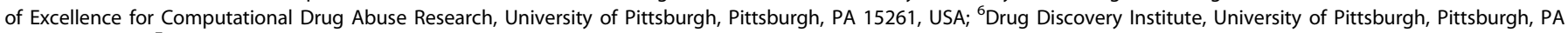
15261, USA and ${ }^{7}$ Departments of Computational Biology and Structural Biology, School of Medicine, University of Pittsburgh, Pittsburgh, PA 15261, USA

Correspondence: Xiang-Qun Xie (xix15@pitt.edu) or Zhi-wei Feng (zhf11@pitt.edu)

These authors contributed equally: Yuan-qiang Wang, Wei-wei Lin, Nan Wu
}

Received: 28 September 2018 Accepted: 17 January 2019

Published online: 27 February 2019 
Various drugs that interact with 5-HT receptor subtypes are marketed for a wide range of serotonin-related indications [10, 11]. For example, vilazodone, a partial agonist of the $5-\mathrm{HT}_{1 \mathrm{~A}}$ receptor, is indicated as a depression treatment; triptans such as sumatriptan and almotriptan act as selective $5-\mathrm{HT}_{1 \mathrm{~B} / 1 \mathrm{D}}$ agonists and are marketed as a migraine reliever; and risperidone, a commonly used antipsychotic, acts as a $5-\mathrm{HT}_{2 \mathrm{~A} / 2 \mathrm{C}}$ antagonist [12]. Moreover, 5-HT receptors are commonly associated with drug abuse due to the crucial roles they play in the development of addiction to various pharmaceutical and recreational drugs. Drugs such as cocaine, amphetamine, methamphetamine, and 3,4-methylenedioxymethamphetamine (MDMA) are known as psychostimulant drugs $[13,14]$. When administered into the human body, psychostimulant drugs can interact with monoamine transporters and lead to an increase in the activity of extracellular 5-HT, dopamine, and noradrenaline in the brain. Increased 5-HT levels in combination with dopamine is a key mechanism of drug addiction [14]. Among the 7 subclasses (5$\mathrm{HT}_{1-7}$ ) of serotonin receptors, $5-\mathrm{HT}_{1 \mathrm{~A}}, 5-\mathrm{HT}_{1 \mathrm{~B}}, 5-\mathrm{HT}_{2 \mathrm{~A}}$, and $5-\mathrm{HT}_{3}$ are especially well known for their association with addictive substances, such as cocaine, amphetamine, methamphetamine, MDMA (ecstasy), morphine/heroin, cannabis, alcohol, and nicotine [15].

Wang et al. [16] reported the crystal structures of the human 5$\mathrm{HT}_{1 \mathrm{~B}}$ receptor bound to its agonists ergotamine and dihydroergotamine. Their structures revealed that these ligands shared similar binding modes in $5-\mathrm{HT}_{1 \mathrm{~B}}$, occupying the orthosteric pocket and an extended binding pocket close to the extracellular loops. They also compared the structure with the $5-\mathrm{HT}_{2 \mathrm{~B}}$ receptor and found that the $5-\mathrm{HT}_{1 \mathrm{~B}}$ receptor displayed a $3 \AA$ outward shift at the intracellular end of TM6, resulting in a more open extended pocket that may explain the subtype selectivity. To investigate the structural basis for biased signaling, Wacker et al. [17] reported the crystal structure of the human $5-\mathrm{HT}_{2 \mathrm{~B}}$ receptor bound to ERG (Protein Data Bank (PDB) entry: 4IB4, resolution: $2.7 \AA$ ) and compared it with the $5-\mathrm{HT}_{1 \mathrm{~B}} / \mathrm{ERG}$ structure. These crystal structures provide a comprehensive structural basis for understanding the receptor-ligand interactions of the 5-HT family subtypes. However, due to high sequence similarity/identity among 5-HT receptors and the unavailability of the threedimensional (3D) structures of the different 5-HT receptors, no reports systematically compare the key residues and selective residues involved in the binding pocket, making it difficult to design subtype-selective serotonergic drugs.

In the present work, we built 3D models for all 5-HT GPCRs based on the existing crystal structure of $5-\mathrm{HT}_{1 \mathrm{~B}} / 5-\mathrm{HT}_{2 \mathrm{~B}} / 5-\mathrm{HT}_{2 \mathrm{C}}$ using homology modeling. To explore our 3D models, we compared the binding results of $5-\mathrm{HT}$ receptors with similar pockets to identify the causes of the variation in binding affinity. Our analysis indicated that the affinity variation may potentially be due to the selective residues located in the binding pocket. Moreover, we carried out molecular dynamics (MD) simulations for all the $5-\mathrm{HT}$ receptors complexed with their reported ligands, and the results were consistent with previous findings. Finally, we conducted off-target prediction for Captagon using systems pharmacology analysis. The findings from the present work provide insights into the detail selectivity of the 5 -HT receptor binding pockets, which could aid drug discovery and design of 5HT receptor-related medication with high specificity to avoid potential addiction and drug abuse.

\section{MATERIALS AND METHODS}

Homology modeling and validation of 5-HT receptors

In this study, we used our previous homology model of human serotonin (5-HTs). Briefly, these models were constructed based on the crystal structure of $5-\mathrm{HT}_{1 \mathrm{~B}}$ (PDB entry: 4IAQ/4IAR, resolution: $2.8 / 2.7 \AA$ ) [16], $5-\mathrm{HT}_{2 \mathrm{~B}}$ (PDB entry: 4IB4, resolution:
$2.7 \AA ̊$ ) [17], and 5- $\mathrm{HT}_{2 \mathrm{C}}$ (PDB entry: $6 \mathrm{BQH}$, resolution: $2.7 \AA$ ) [18]. The sequences of the human GPCRs were obtained from UniProtKB/Swiss-Prot (https://www.uniprot.org/uniprot/). We truncated some residues from the $\mathrm{N}$ and $\mathrm{C}$ terminals. As the third intracellular loop (between helix 5 and helix 6) has a long, flexible sequence, we only kept $\sim 15$ residues. Then, Modeller 9.18 [19] was used to construct the homology models by (a) searching and selecting template(s) for the target protein, (b) conducting sequence alignment between the target and template(s), (c) adjusting the sequence alignment using the residue tables from the GPCR database (GPCRdb) [20] (http://gpcrdb.org/ residue/residuetable), and (d) building and evaluating the homology models.

Docking study of ligands and receptors

We adopted the MOLCAD module implemented in SYBYL-X 1.3 to explore the potential binding pockets of receptors. The docking program Surflex-Dock GeomX (SFXC) in SYBYL-X 1.3 was used to construct receptor-ligand complexes in which the docking scores were expressed in $-\log _{10}\left(K_{\mathrm{d}}\right)$ [21]. The main protocols or parameters of docking were addressed in our previous publications [22-25]. Briefly, the docking parameters were as follows: (a) the "number of starting conformations per ligand" was set to 10, and the "number of max conformations per fragment" was set to 20; (b) the "maximum number of rotatable bonds per molecule" was set to 100 ; (c) flags were turned on at "pre-dock minimization", "post-dock minimization", "molecule fragmentation", and "soft grid treatment"; (d) "activate spin alignment method with density of search" was set to 9.0; and (e) the "number of spins per alignment" was set to 12 .

\section{MD simulations}

The 5-HT receptors complexed with ligands were set up for MD simulation. For example, the $5-\mathrm{HT}_{2 b}$ receptor complexed with inhibitor BF-1 system was put in $0.15 \mathrm{M} \mathrm{NaCl}$ solution and formed a cubic water box, which included 26,481 water molecules, $72 \mathrm{Na}^{+}$ ions, and $82 \mathrm{Cl}^{-}$ions. The initial configurations of the protein receptors and ligands were taken from docking studies. The sizes of the initial simulation boxes were $\sim 100 \AA \times 100 \AA \times 100 \AA$. The other systems were set up with the same protocol.

The AMBER ff14SB force field [26] was applied to proteins. Water molecules were treated with the TIP3P (transferable intermolecular potential with 3 points) water model [27]. The partial atomic charges of ligands were derived using the semi-empirical with bond charge correction (AM1-BCC) method $[28,29]$. The other force field parameters were obtained from GAFF in AMBER16 [29]. The residue topologies for ligands were prepared using the ANTECHAMBER module.

The MD simulations were carried out using the PMEMD.mpi and PMEMD.cuda modules in the AMBER16 [30-32] package. First, several minimization steps were conducted for the systems to avoid possible steric crashes. Then, each system was gradually heated from $0 \mathrm{~K}$ to $300 \mathrm{~K}$ during the heating stage and maintained at $300 \mathrm{~K}$ during the subsequent equilibrium and production stages. A time step of $2 \mathrm{fs}$ was used for the heating stage, equilibrium stage, and the entire production stage. A periodic boundary condition was employed to maintain constant temperature and the pressure) ensembles. The pressure was set at $1 \mathrm{~atm}$ and controlled by the anisotropic $\left(x^{-}, y^{-}, z^{-}\right)$ pressure scaling protocol with a pressure relaxation time of $1 \mathrm{ps}$. The temperature was regulated using Langevin dynamics with a collision frequency of $2 \mathrm{ps}^{-1}[33,34]$. The particle mesh Ewald (PME) method $[35,36]$ was adopted to handle long-range electrostatics and a $10 \AA$ cutoff was set to treat real-space interactions. All covalent bonds involving hydrogen atoms were constrained with the SHAKE algorithm [37]. Each system was subject to a 50 ns MD simulation and the trajectory of simulated systems was saved every 100 ps. 
a

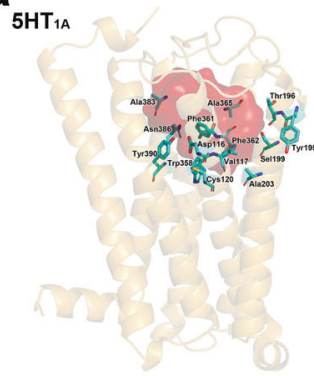

e

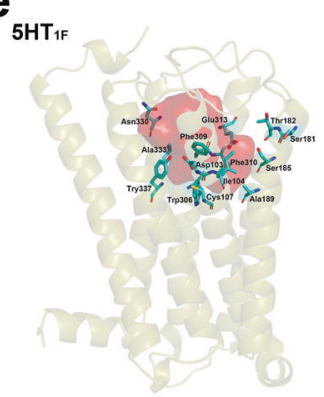

i

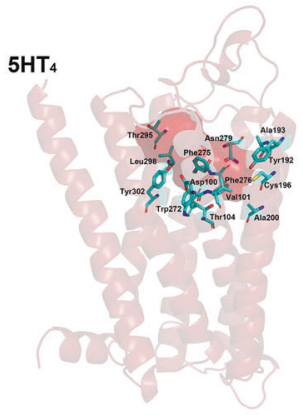

b

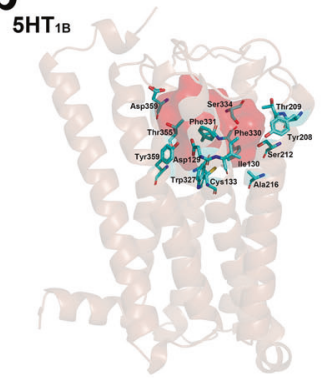

f

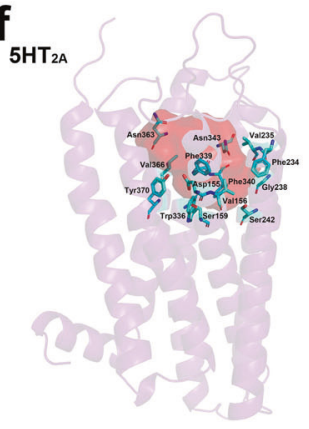

$\mathbf{j}_{5 \mathrm{HT}}$

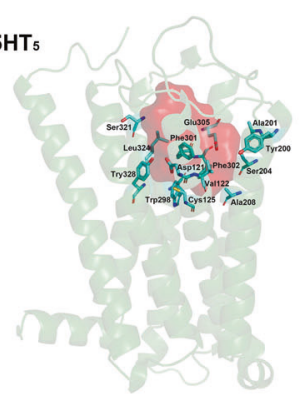

C

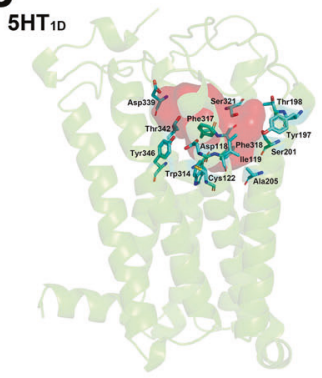

$\mathbf{g}_{\text {sH } \mathrm{Tan}}$

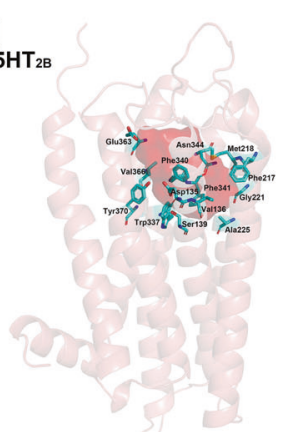

k

$5 \mathrm{HT}_{6}$

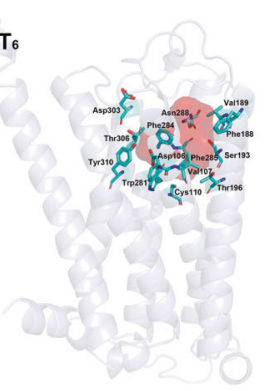

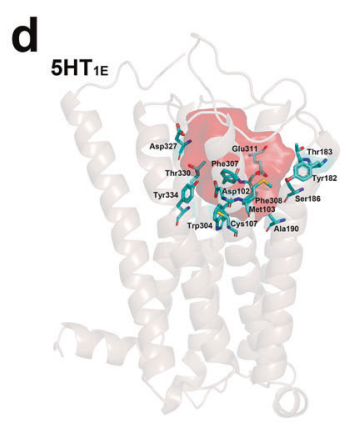

h
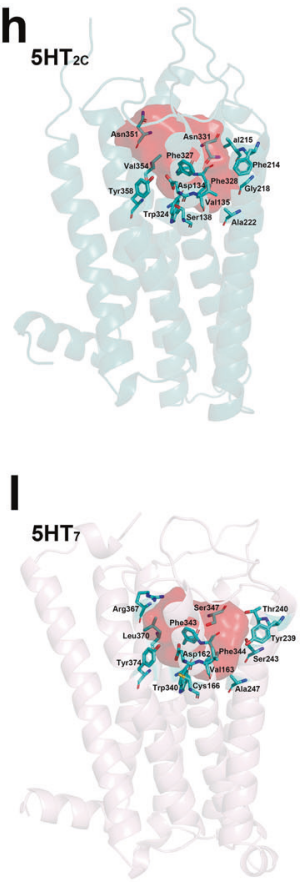

Fig. 1 The three-dimensional (3D) structure, binding pocket, and key residues of 5-hydroxytryptamine (5-HT) receptors family. a The binding pocket and key residues at 5-HT $1 \mathrm{~A}$. b The binding pocket and key residues at 5- $\mathrm{HT}_{1 \mathrm{~B}}$. c The binding pocket and key residues at 5- $\mathrm{HT} \mathrm{T}_{1 \mathrm{D}}$. $\mathbf{d}$ The binding pocket and key residues at 5- $\mathrm{HT}_{1 \mathrm{E}}$. e The binding pocket and key residues at $5-\mathrm{HT}_{1 \mathrm{~F}}$. $\mathbf{f}$ The binding pocket and key residues at $5-\mathrm{HT} \mathrm{T}_{2 \mathrm{~A}}$. $\mathbf{g}$ The binding pocket and key residues at $5-\mathrm{HT}_{2 \mathrm{~B}}$. $\mathbf{h}$ The binding pocket and key residues at $5-\mathrm{HT}_{2 \mathrm{C}}$. $\mathbf{i}$ The binding pocket and key residues at $5-\mathrm{HT}_{4}$. j The binding pocket and key residues at $5-\mathrm{HT}_{5}$. $\mathbf{k}$ The binding pocket and key residues at $5-\mathrm{HT}_{6}$. I The binding pocket and key residues at $5-\mathrm{HT}_{7}$. The binding pockets at $5-\mathrm{HT}$ receptors are generally formed by transmembrane helix III, $\mathrm{V}, \mathrm{VI}$, and $\mathrm{VII}$

Molecular mechanics/generalized born surface area (MM/GBSA) calculation

For the saved trajectories of MD simulations, the MM/GBSA [3844] method was used to calculate the binding energies of receptors treated with different ligands. A total of 300 snapshots were extracted from each trajectory every 100 ps from 20 to $50 \mathrm{~ns}$ to calculate the mean binding energy. The formula is as follows:

$$
\Delta E_{\text {bind }}=\Delta E_{\mathrm{MM}}+\Delta E_{\mathrm{SOL}}=\Delta E_{\mathrm{MM}}+\Delta E_{\mathrm{GB}}+\Delta E_{\mathrm{SA}} \text {, }
$$

where $\triangle E_{\mathrm{bind}}$ is the binding energy and $\triangle E_{\mathrm{MM}}$ denotes the sum of the molecular mechanical energies in vacuo and can be further divided into the contributions from electrostatic, van der Waals, and internal energies. This term could be computed using the molecular mechanics method. $\triangle E_{\mathrm{SO}}$ is the solvation energy, which includes the polar solvation energy $\left(\triangle E_{\mathrm{GB}}\right)$ calculated with the generalized born (GB) approximation model $[45,46]$ and the non-polar part $\left(\triangle E_{S A}\right)$ obtained by fitting solvent accessible surface area (SASA) [47] with the linear combinations of pairwise overlaps (LCPO) model $[48,49]$. Additionally, the energies of each residue were decomposed into the backbone and side-chain atoms. The energy decomposition can be analyzed to determine the contributions of the key residues to the binding [50].

Hallucinogen-specific chemogenomics knowledgebase and systems pharmacology analysis

We constructed a hallucinogen-specific chemogenomics database [51] that can be used for target, off-target, additional identification, and systems pharmacology analysis of small molecules and their potential targets. Several in-house chemoinformatics tools were utilized, including TargetHunter, HTDocking, and the blood-brain barrier (BBB) predictor $[52,53]$. HallucinogenPlatform (http://www.cbligand.org/hallucinogen/) collected 144 hallucinogen-related target proteins and 145 chemical compounds associated with these targets in 6721 assays and 23,598 references.

In the present work, we applied our HallucinogenPlatform and established chemoinformatics tools such as HTDocking to perform systems pharmacological analysis for Captagon. First, Captagon 
Table 1. Key residues involved in the binding pocket of 5-hydroxytryptamine (5-HT) receptors

\begin{tabular}{|c|c|c|c|c|c|c|c|c|c|c|c|c|c|}
\hline No. & Location & $5-\mathrm{HT}_{1 \mathrm{~A}}$ & 5- $\mathrm{TH}_{1 \mathrm{~B}}$ & $5-\mathrm{HT}_{1 \mathrm{D}}$ & $5-\mathrm{HT}_{1 \mathrm{E}}$ & $5-\mathrm{TH}_{1 \mathrm{~F}}$ & $5-\mathrm{HT}_{2 \mathrm{~A}}$ & $5-\mathrm{HT}_{2 \mathrm{~B}}$ & $5-\mathrm{HT}_{2 \mathrm{C}}$ & $5-\mathrm{HT}_{4}$ & $5-\mathrm{HT}_{5}$ & $5-\mathrm{HT}_{6}$ & $5-\mathrm{HT}_{7}$ \\
\hline 2 & $3 \times 33$ & V117 & 1130 & 1119 & M103 & 1104 & V156 & V136 & V135 & V101 & V122 & V107 & V163 \\
\hline 4 & $5 \times 39$ & Y195 & Y208 & Y197 & Y182 & S181 & F234 & F217 & F214 & Y192 & Y200 & F188 & Y239 \\
\hline 5 & $5 \times 40$ & T196 & T209 & T198 & T183 & T182 & V235 & M218 & V215 & A193 & A201 & V189 & $\mathrm{T} 240$ \\
\hline 6 & $5 \times 43$ & S199 & S212 & S201 & S186 & S185 & G238 & G221 & G218 & C196 & S204 & S193 & S243 \\
\hline 8 & $6 \times 48$ & W358 & W327 & W314 & W304 & W306 & W336 & W337 & W324 & W272 & W298 & W281 & W340 \\
\hline 9 & $6 \times 51$ & F361 & F330 & F317 & F307 & F309 & F339 & F340 & F327 & F275 & F301 & F284 & F343 \\
\hline 10 & $6 \times 52$ & F362 & F331 & F318 & F308 & F310 & F340 & F341 & F328 & F276 & F302 & F285 & F344 \\
\hline 11 & $6 \times 55$ & A365 & S334 & S321 & E311 & E313 & N343 & N344 & N331 & N279 & E305 & N288 & S347 \\
\hline 12 & $7 \times 35$ & A383 & D352 & D339 & D327 & N330 & N363 & E363 & N351 & T295 & S321 & D303 & R367 \\
\hline
\end{tabular}

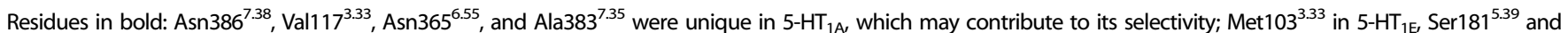

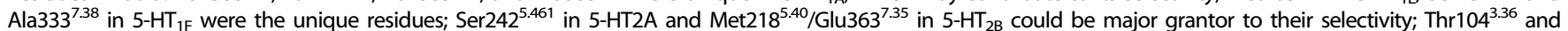
Cys $196^{5.461}$ in $5-\mathrm{HT}_{4}$, Ser321 ${ }^{7.35}$ in $5-\mathrm{HT}_{5}, \mathrm{Thr}_{196^{5.461}}$ in $5-\mathrm{HT}_{6}$, and $\mathrm{Arg} 367^{7.35}$ in $5-\mathrm{HT}_{7}$ were unique to each receptor and played an essential role in their binding process

was docked into the target protein pockets. We matched these predicted target proteins to Captagon according to their docking scores. targets with higher docking scores may have higher binding affinities and therefore a greater chance of interacting with Captagon. Next, we mapped out a pharmacological network of interactions between drug compounds and target proteins at the molecular level $[54,55]$. Cytoscape 3.4.0 [56] was used to generate, analyze, and visualize the network of targets and drugs/ compounds, as described previously [55].

\section{RESULTS}

Overview of the 5-HT receptor family binding pockets

Fig. 1 shows the 3D structures of 5-HT receptor variations constructed in the present study based on the crystal structures of $5-\mathrm{HT}_{1 \mathrm{~B}} / 5-\mathrm{HT}_{2 \mathrm{~B}} / 5-\mathrm{HT}_{2} \mathrm{C}$. The binding pocket and key amino acid residues associated with the binding pocket of the receptors are also indicated in Fig. 1. These binding pockets were generally composed of transmembrane helices III, V, VI, and VII. Being classified as receptors within the same family, 5-HT receptors share many commonalities in their amino acid residues. These conserved amino acid residues include aspartate (Asp) on helix III position 32 (3.32), tryptophan (Trp) on helix VI position 48 (6.48), phenylalanine (Phe) at helix VI position 51 (6.51) and 52 (6.52), and tyrosine (Tyr) on helix VII position 42 (7.42). These common amino acid key residues can be used to explain the similar functionality and affinity between these receptors. These key residues involved in the binding pocket of 5- $\mathrm{HT}$ receptors are listed in Table 1. The unique residues in individual receptors are highlighted in red and may play a key role in their selectivity (see below).

$5-\mathrm{HT}_{1 \mathrm{~A}}$ and $5-\mathrm{HT}_{7}$ bound with selective $5-\mathrm{HT}_{1 \mathrm{~A}}$ antagonist NAD299

The $5-\mathrm{HT}_{1 \mathrm{~A}}$ and $5-\mathrm{HT}_{7}$ are subtypes of the $5-\mathrm{HT}$ serotonin receptor family that have different pharmacological mechanisms. To explore the differences in selectivity, we performed and compared molecule docking between these two receptors and NAD-299 (a selective $5-\mathrm{HT}_{1 \mathrm{~A}}$ antagonist [57], Table 2).

As shown in Fig. 2, the binding pocket of $5-\mathrm{HT}_{1 \mathrm{~A}} / 5-\mathrm{HT}_{7}$ was mainly composed of TM3, TM5, TM6, and TM7, and was defined by the reported key residues shown in Table 1. The binding pocket of
5- $\mathrm{HT}_{1 \mathrm{~A}}$ and $5-\mathrm{HT}_{7}$ shared many similar residues, such as Asp116/ Asp162 $2^{3.32}$ Cys120/Cys166 3.36 , Ser199/Ser243.43, Ala203/ Ala247.461, Trp358/Trp340.48', Phe361/Phe343 ${ }^{6.51}$ ', Phe362/ Phe344.52, and Tyr390/Tyr374 ${ }^{7.42}$. NAD-299 resulted in similar conformations when docked into both receptors, with the chromane structure facing TM7 and four carbon rings facing TM5 and TM6. Although 5- $\mathrm{HT}_{1 \mathrm{~A}}$ and $5-\mathrm{HT}_{7}$ share similar residues, their binding affinity with NAD-299 is very different. The binding affinity between $5-\mathrm{HT}_{1 \mathrm{~A}}$ and NAD-299 is $0.59 \mathrm{nM}$ (Table 2), whereas the binding affinity between NAD-299 and $5-\mathrm{HT}_{7}$ is much weaker (1900 nM, Table 2). We suggest that this drastic difference in binding affinity is due to the slight variation in key residues related to the binding pocket of the $5-\mathrm{HT}$ receptor subtypes. A major distinction in interactions that could contribute to this large difference in binding affinity is the ability to form a strong hydrogen bond between NAD-299 and the binding pocket. When docking NAD-299 to the binding pocket of $5-\mathrm{HT}_{1 \mathrm{~A}}$, three potential hydrogen bonds involving the oxygen on the amide group of NAD-299 were observed, with bond lengths of $\sim 2.1 \AA$ (with oxygen on Asp116 ${ }^{3.32}$ ), 3.4 $\AA$ (with nitrogen on Asn $386^{7.38}$ ), and $\sim 3.6 \AA$ (with oxygen on Tyr390 ${ }^{7.42}$ ), while only one possible hydrogen bond was observed in the binding pocket of $5-\mathrm{HT}_{7}$ between the nitrogen on the amide group of NAD-299 and the single bonded oxygen on the carboxyl group of Asp $162^{3.32}$ ( $2.9 \AA)$. The different interactions of the unique residues Asn386/ Leu370 ${ }^{7.38}$ greatly contributed to the different binding affinity. Compared to Asp $162^{3.32}$, the lack of an additional nitrogen on Leu370 7.38 in close vicinity of the oxygen on the amide group of NAD-299 also contributed to the inability to form a hydrogen bond. Aside from the difference in hydrogen bonds, the number of hydrophobic interactions between NAD-299 and the two binding pockets varies drastically. There were 14 hydrophobic interactions between NAD-299 and the binding pocket of 5-HT (some of which are not shown in Fig. 2) compared to only 6 hydrophobic interactions in the binding pocket of $5-\mathrm{HT}_{7}$. The potential selective residues, including Ala $365^{6.55}$ and Ala383 $33^{7.35}$ on $5-\mathrm{HT}_{1 \mathrm{~A}}$, greatly contributed to the hydrophobic interaction. This difference in the number of hydrophobic interactions is another key factor in the selectivity of the binding pockets, which can also be explained by the difference in amino acid residues in the binding pocket and the variation in the conformations of similar residues. 
$5-\mathrm{HT}_{1 \mathrm{~B}}, 5-\mathrm{HT}_{1 \mathrm{D}}$, and $5-\mathrm{HT}_{4}$ bound with selective $5-\mathrm{HT}_{1 \mathrm{~B}}$ inverse agonist SB-236057

The $5-\mathrm{HT}_{1}$ subgroup is one of the seven subgroups in the $5-\mathrm{HT}$ receptor subfamily. Individual subtypes within the subgroup closely resemble each other structurally, functionally, and transductionally. To explore the selectivity among these receptors, we performed molecular docking between the selective $5-\mathrm{HT}_{1 \mathrm{~B}}$ inverse agonist SB-236057 [58] (Table 2) and 5- $\mathrm{HT}_{1 \mathrm{~B}} / 5-\mathrm{HT}_{1 \mathrm{D}}$. We also performed docking between SB-236057 (Table 2) and 5- $\mathrm{HT}_{4}$ and compared the differences.

As shown in Fig. 3, the binding pocket of all three receptors as mainly composed of TM3, TM5, TM6, and TM7, and the reported key residues are shown in Table 1 . The binding pose of SB236057 in all three pockets was very similar (Fig. 3), with the oxadiazole structure and two benzene rings parallel to the transmembrane structure facing up and away from the residues and the tricyclic structure perpendicular to the transmembrane helixes.

The 5- $\mathrm{HT}_{1 \mathrm{~B}}$ and $5-\mathrm{HT}_{1 \mathrm{D}}$ share all the key amino acid residues at the same locations on the transmembrane domains (Fig. 3). The binding pocket of $5-\mathrm{HT}_{1 \mathrm{~B}}$ and $5-\mathrm{HT}_{1 \mathrm{D}}$ is mainly composed of Asp129/Asp118 ${ }^{3.32}$, Ile130/lle1193.33, Cys133/Cys122.36, Tyr208/ Tyr197 $7^{5.39}$, Thr209/Thr198 $8^{5.40}$, Ser212/Ser201 ${ }^{5.43}$, Ala216/

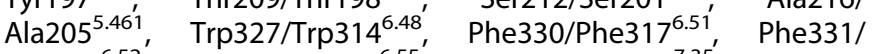
Phe321 $1^{6.52}$ ', Ser334/Ser321 $1^{6.55^{\prime}}$ Asp352/Asp339 $9^{7.35^{\prime}}$, Thr355/ Thr342 ${ }^{7.38^{\prime}}$, and Tyr390/Tyr374 ${ }^{7.42}$. Although the binding pockets of $5-\mathrm{HT}_{1 \mathrm{~B}} / 5-\mathrm{HT}_{1 \mathrm{D}}$ consist of identical key residues, we found a large difference in the binding affinity between SB-236057 and 5$\mathrm{HT}_{1 \mathrm{~B}} / 5-\mathrm{HT}_{1 \mathrm{D}}(\sim 6.31 \mathrm{nM}$ and $\sim 501.19 \mathrm{nM}$, respectively, Table 2$)$. Although the residues in the binding pocket of $5-\mathrm{HT}_{1 \mathrm{~B}}$ and $5-\mathrm{HT}_{1 \mathrm{D}}$ were consistent, we observed that the conformation of the side chain in some particular residues may play an important role in their selectivity. When docking SB-236057 into $5-\mathrm{HT}_{1 \mathrm{~B}}$, one hydrogen bond $(3.9 \AA)$ formed between Cys133.36 and the oxygen on the tricyclic structure of SB-236057; another hydrogen bond $(3.5 \AA$ ) formed between the single bonded oxygen on the carboxyl group of the Ser2 $12^{5.43}$ and the nitrogen on the tricyclic structure of SB-236057. However, when docking SB-236057 to 5$\mathrm{HT}_{1 \mathrm{D}}$, Ser $201^{5.43}$ was the only residue capable of forming a hydrogen bond with SB-236057. The key difference was the conformation of Cys133/Cys122 3.36 in the binding pocket. In the binding pocket of $5-\mathrm{HT}_{1 \mathrm{~B}}$, Cys $133^{3.36}$ was in the conformation where the silicone faced SB-236057, making the hydrogen bond feasible, while in the binding pocket of 5-HT 1 D, Cys $122^{3.36}$ faced away from the small molecule, making the formation of a hydrogen bond difficult.

The binding affinity between SB-236057 and 5- $\mathrm{HT}_{4}$ is 3981.07 $\mathrm{nM}$ (Table 2), which is weaker than that of $5-\mathrm{HT}_{1 \mathrm{~B}}$. This difference in selectivity between $5-\mathrm{HT}_{1 \mathrm{~B}}$ and $5-\mathrm{HT}_{4}$ can be explained by the variation in binding residues. The main distinction in the key 5 $\mathrm{HT}_{1 \mathrm{~B}}$ and $5-\mathrm{HT}_{4}$ residues include lle130/Val1013.33, Cys133/ Thr1043.36, Thr209/Ala193.40, Ser212/Cys196 ${ }^{5.43}$, Ser334/ Asn279 ${ }^{6.55}$, Asp352/Thr295 7.35 , and Thr355/Leu298 ${ }^{7.38}$. As shown in Fig. 3, two potential strong hydrogen bonds can be observed in the binding pocket of $5-\mathrm{HT}_{4}$ but, unlike $5-\mathrm{HT}_{1 \mathrm{~B}}, 5-\mathrm{HT}_{4}$ has a threonine $\left(\mathrm{Thr} 104^{3.36}\right)$ in place of the cysteine at helix III position 36 (3.36), which results in the formation of a hydrogen bond between the oxygen on the hydroxyl group of Thr104.36 and the oxygen on the tricyclic structure of SB-236057. Compared to the hydrogen bond between Cys $133^{3.36}$ and SB-236057 in the binding pocket of $5-\mathrm{HT}_{1 \mathrm{~B}}$, the hydrogen bond between Thr104.36 and SB236057 has a bond angle of almost 90 degrees, resulting in a weaker binding affinity.

$5-\mathrm{HT}_{7}$ and $5-\mathrm{HT}_{2}$ subgroups bound with selective $5-\mathrm{HT}_{2 \mathrm{~B}}$ receptor agonist BF-1

Each subtype in the $5-\mathrm{HT}_{2}$ subgroup closely resembles each other structurally, functionally, and transductionally. There are three 


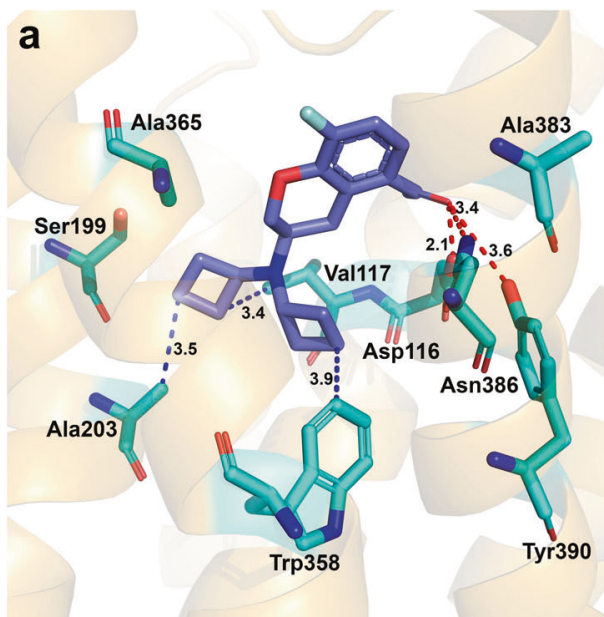

5-HT1A/NAD-299

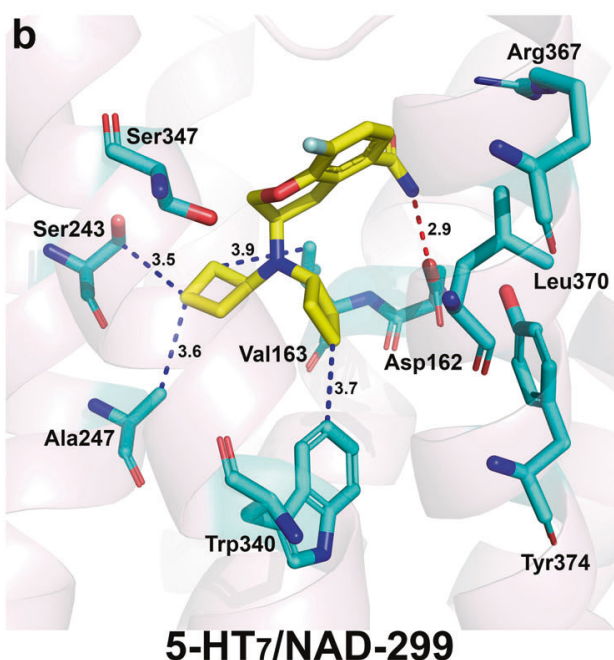

5-HT7/NAD-299

Fig. 2 The interaction between NAD-299 and 5- $\mathrm{HT}_{1 \mathrm{~A}}$ and 5- $\mathrm{HT}_{7}$. a The interactions between 5- $\mathrm{HT}_{1 \mathrm{~A}}$ and NAD-299. $\mathbf{b}$ The interactions between $5-\mathrm{HT}_{7}$ and NAD-299. The binding affinity between $5-\mathrm{HT}_{1 \mathrm{~A}}$ and NAD-299 is $0.59 \mathrm{nM}$, while the binding affinity between NAD-299 and 5-HT only $1900 \mathrm{nM}$. Ala383/Arg367 7.35 and Asn386/Leu370 ${ }^{7.38}$ contributed to the selectivity. 5-HT 5-hydroxytryptamine

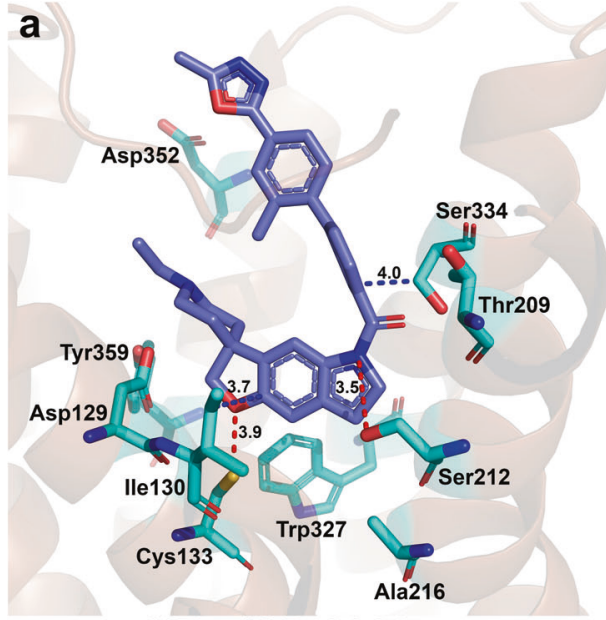

5-HT1B/SB-236057

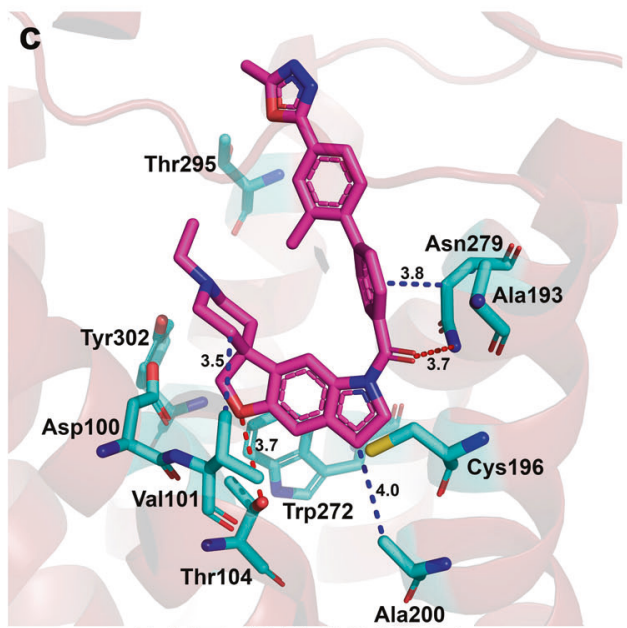

5-HT4/SB-236057

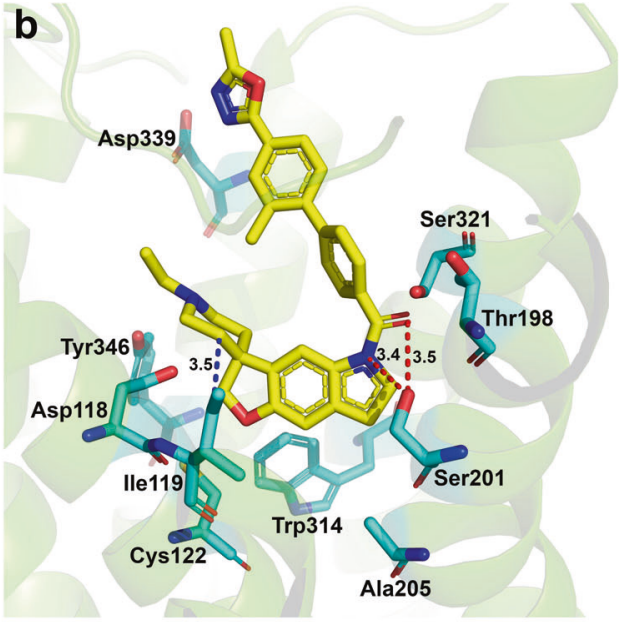

5-HT1D/SB-236057

Fig. 3 The interaction between SB-236057 and 5- $\mathrm{HT}_{1 \mathrm{~B}}, 5-\mathrm{HT}_{1 \mathrm{D}}$ and 5- $\mathrm{HT}_{4}$. a The interactions between 5-HT $1 \mathrm{~B}$ and SB-236057. b The interactions between 5-HT $1 \mathrm{D}$ and SB-236057. c The interations between 5- $\mathrm{HT}_{4}$ and SB-236057. The binding affinity between SB-236057 and $5-\mathrm{HT}_{1 \mathrm{~B}} / 5-\mathrm{HT}_{1 \mathrm{D}}$ is $\sim 6.31 \mathrm{nM}$ and $\sim 501.19 \mathrm{nM}$, while the binding affinity between SB-236057 and 5- $\mathrm{HT}_{4}$ is $\sim 3981.07 \mathrm{nM}$. $5-\mathrm{HT}$ 5-hydroxytryptamine 

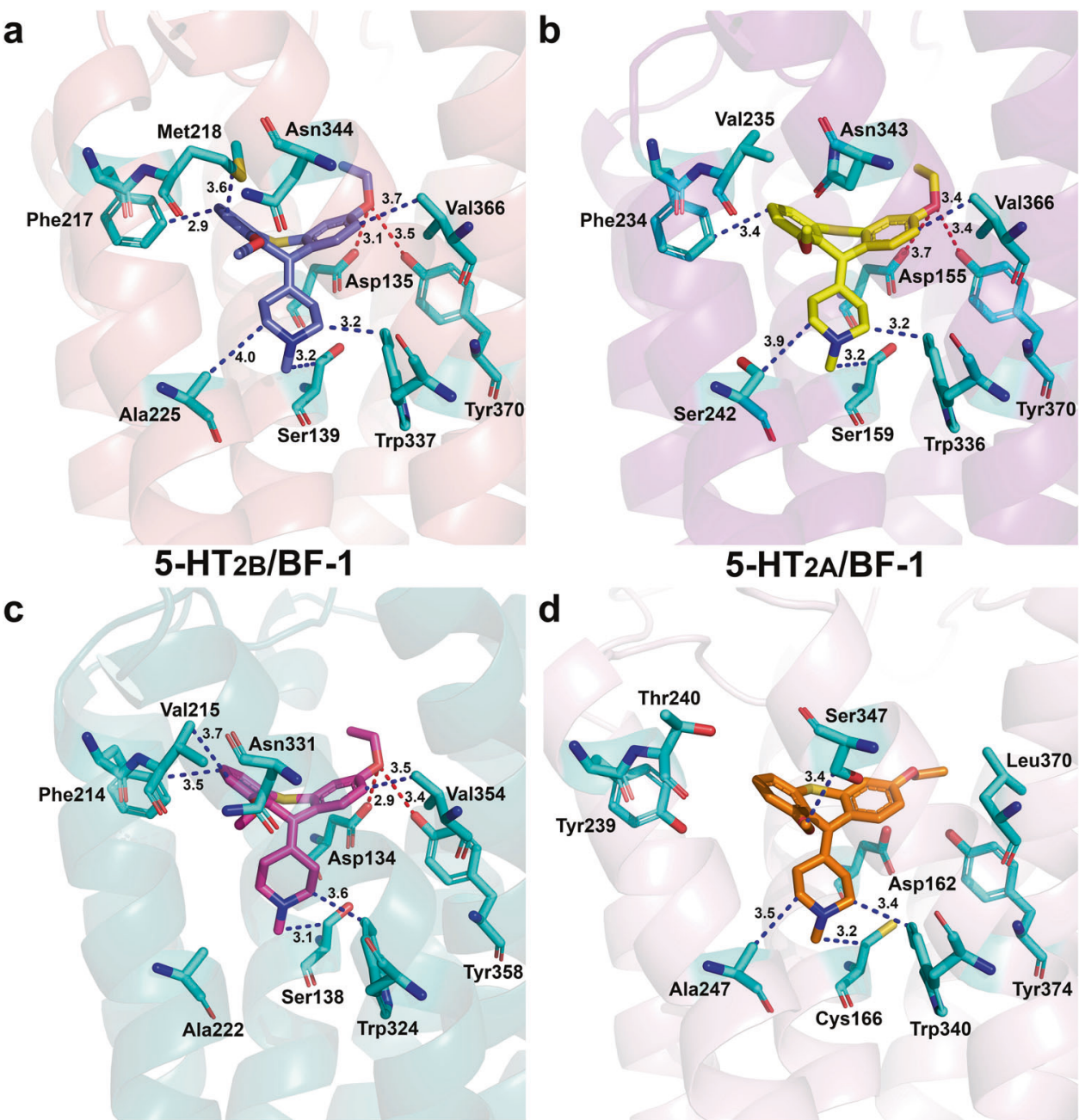

\section{5-HT2C/BF-1}

\section{5-HT7/BF-1}

Fig. 4 The interaction between $\mathrm{BF}-1$ and $5-\mathrm{HT}_{2 \mathrm{~B}}, 5-\mathrm{HT}_{2 \mathrm{~A}}, 5-\mathrm{HT}_{2}$, and $5-\mathrm{HT}_{7}$. a The interactions between 5- $\mathrm{HT}$ 2B and $\mathrm{BF}-1$. b The interactions between $5-\mathrm{HT}_{2 \mathrm{~A}}$ and $\mathrm{BF}-1$. $\mathrm{c}$ The interactions between $5-\mathrm{HT}_{2 \mathrm{C}}$ and $\mathrm{BF}-1$. d The interactions between $5-\mathrm{HT}$ and $\mathrm{BF}-1$. The binding affinity of $\mathrm{BF}-1$ is $\sim 0.09 \mathrm{nM}$ in $5-\mathrm{HT}_{2 \mathrm{~B}}, \sim 2.82 \mathrm{nM}$ in $5-\mathrm{HT}_{2 \mathrm{~A}}, \sim 22.91 \mathrm{nM}$ in 5- $\mathrm{HT}_{2 \mathrm{C}}$, and $~ 66.07 \mathrm{nM}$ in 5- $\mathrm{HT}_{7}$. 5- $\mathrm{HT}$ 5-hydroxytryptamine

subtypes within the $5-\mathrm{HT}_{2}$ subgroup: $5-\mathrm{HT}_{2 \mathrm{~A}}, 5-\mathrm{HT}_{2 \mathrm{~B}}$, and $5-\mathrm{HT}_{2} \mathrm{C}$. The key residues for these receptors had been identified as shown in Table 1. The $5-\mathrm{HT}_{2}$ subtypes shared similar residues. The variations among the key residues include: (1) $5-\mathrm{HT}_{2 \mathrm{~B}}$ has methionine on helix $\mathrm{V}$ position 40 (Met218 ${ }^{5.40}$ ), while the other two receptor subtypes have valine; (2) $5-\mathrm{HT}_{2 \mathrm{~A}}$ has serine on helix $\mathrm{V}$ position 461 (Ser242 $2^{5.461}$ ), while the other two receptor subtypes have alanine; and (3) $5-\mathrm{HT}_{2 \mathrm{~B}}$ has glutamic acid on helix VII position

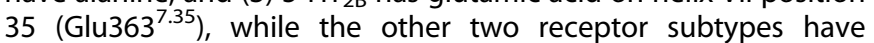
asparagine acid. Although the subtypes within this subgroup are greatly similar, the selectivity among these subtypes is still reported. To explore it, we performed molecular docking between BF-1 [59] (the selective $5-\mathrm{HT}_{2 \mathrm{~B}}$ receptor agonist) and all three $5-\mathrm{HT}_{2}$ receptors. Additionally, we also docked $\mathrm{BF}-1$ to $5-\mathrm{HT}_{7}$ for further analysis.

The binding affinity of BF-1 (Table 2) is $\sim 0.09 \mathrm{nM}$ in $5-\mathrm{HT}_{2 \mathrm{~B}}$, $\sim 2.82 \mathrm{nM}$ in $5-\mathrm{HT}_{2 \mathrm{~A}}$, and $\sim 22.91 \mathrm{nM}$ in $5-\mathrm{HT}_{2 \mathrm{C}}$. As shown in Fig. 4, the binding pose of $\mathrm{BF}-1$ was almost the same in these receptors. To future explore this binding result, we looked at the binding pocket of each $5-\mathrm{HT}_{2}$ receptor. All $5-\mathrm{HT}_{2}$ receptors showed the ability to form two hydrogen bonds with BF-1 at the same position: one between oxygen on $\mathrm{BF}-1$ and the oxygen on the Asp155/Asp135/Asp134 3.32 ( 3.7 $\AA, \sim 3.1 \AA$, and $2.9 \AA$ respectively), and another between the same oxygen on BF-1 and the Tyr370/ Tyr370/Tyr358 ${ }^{7.42}(\sim 3.4 \AA, \sim 3.5 \AA$, and $3.4 \AA$ respectively). Moreover, hydrophobic interaction played an important role in their selectivity. $5-\mathrm{HT}_{2 \mathrm{~A}}, 5-\mathrm{HT}_{2 \mathrm{~B}}$, and $5-\mathrm{HT}_{2 \mathrm{C}}$ shared similar hydrophobic interactions. However, the residue at position 5.40 at $5-\mathrm{HT}_{2 \mathrm{~B}}$ is Met2 $18^{5.40}$ and different from that of $5-\mathrm{HT}_{2 \mathrm{~A}}$ and $5-\mathrm{HT}_{2 \mathrm{C}}(\mathrm{Val} 235 /$ Val2 $\left.15^{5.40}\right), 5-\mathrm{HT}_{2 \mathrm{~B}}$ was able to form an additional hydrophobic interaction, which Met $218^{5.40}$ may contribute to the selectivity of $5-\mathrm{HT}_{2 \mathrm{~B}}$.

The binding affinity between BF-1 and $5-\mathrm{HT}_{7}$ is $\sim 66.07 \mathrm{nM}$ (Table 1). When comparing $5-\mathrm{HT}_{2 \mathrm{~B}}$ and $5-\mathrm{HT}_{7}$, we noticed seven different residues (Ser139/Cys166 ${ }^{3.36}$, Met218/Thr240 ${ }^{5.40}$, Val366/ Leu370 ${ }^{7.38}$ ) and interactions between them, resulting in different binding affinity of BF-1.

$5-\mathrm{HT}_{2 \mathrm{~A}}, 5-\mathrm{HT}_{2 \mathrm{~B}}, 5-\mathrm{HT}_{2 \mathrm{C}}$ and $5-\mathrm{HT}_{1 \mathrm{D}}$ subgroup bound with selective $5-\mathrm{HT}_{2 \mathrm{C}}$ receptor agonist SB-242084

As shown in Fig. 5, the binding pocket of $5-\mathrm{HT}_{2 \mathrm{~A}} / 5-\mathrm{HT}_{2 \mathrm{~B}} / 5-\mathrm{HT}_{2 \mathrm{C}} / 5-$ $\mathrm{HT}_{1 \mathrm{D}}$ mainly consisted of TM3, TM5, TM6, and TM7 (Table 1). Similar key residues among the binding pockets of these four receptors included Asp155/Asp135/Asp134/Asp118 ${ }^{3.32}$, Phe339/ Phe340/Phe327/Phe317 6.51, Phe340/Phe341/Phe328/Phe318 ${ }^{6.52,}$ and Tyr370/Tyr370/Tyr358/Tyr346 ${ }^{7.42}$. Even with many similarities, 

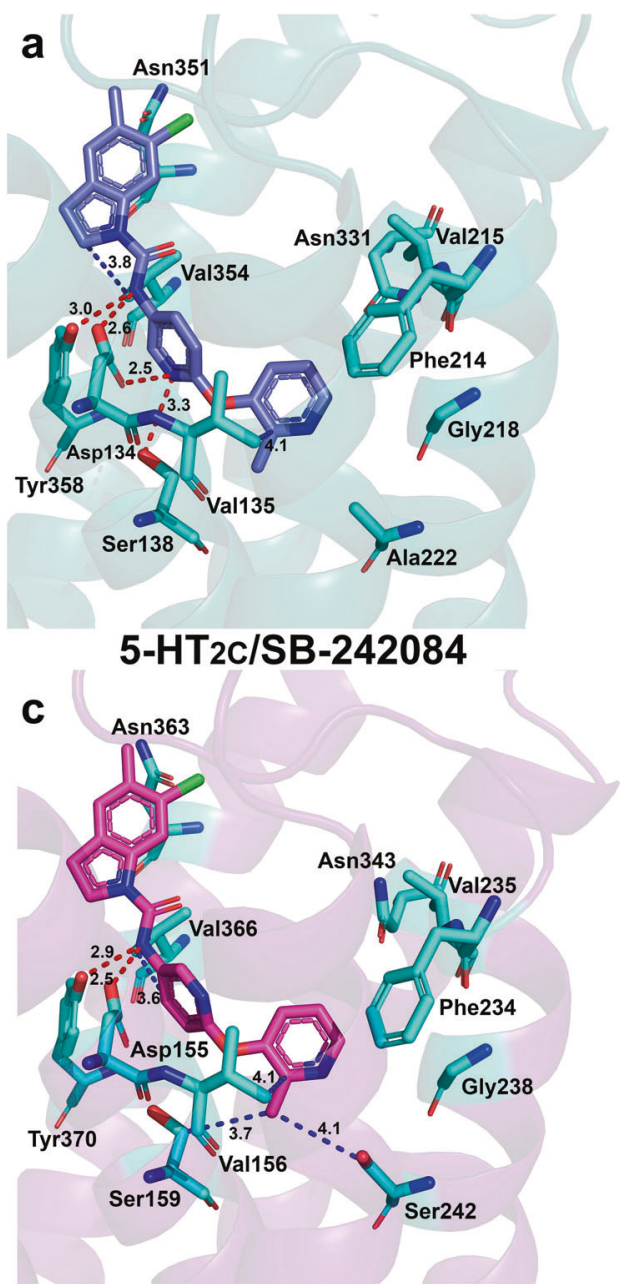

5-HT2A/SB-242084

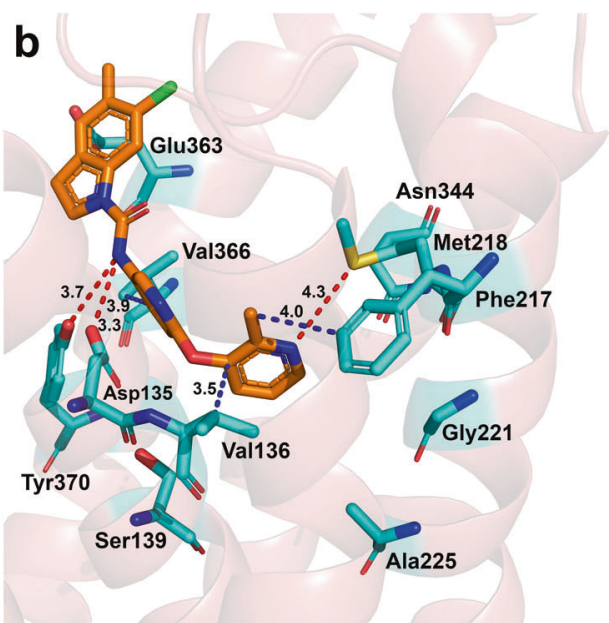

5-HT2B/SB-242084

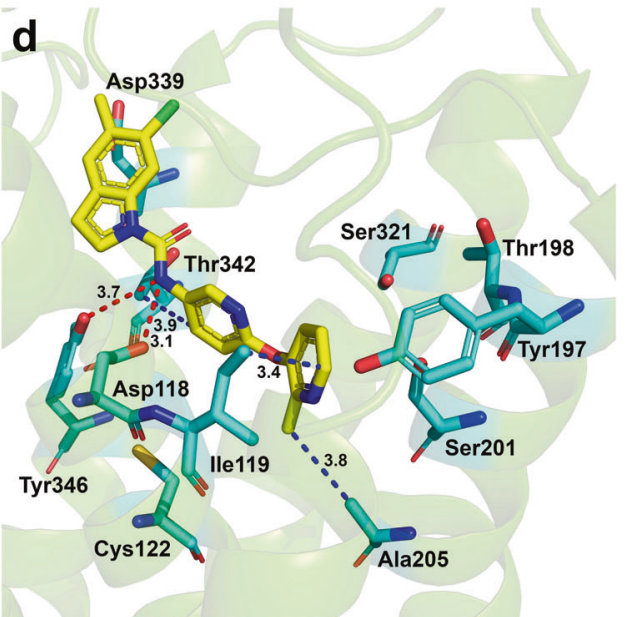

5-HT1D/SB-242084

Fig. 5 The interaction between SB-242084 and 5- $\mathrm{HT}_{2}, 5-\mathrm{HT}_{2 \mathrm{~B}}, 5-\mathrm{HT}_{2 \mathrm{~A}}, 5-\mathrm{HT}$. . a The interactions between 5- $\mathrm{HT} 2 \mathrm{C}$ and $\mathrm{SB}-242084$. b The interactions between $5-\mathrm{HT}_{2 B}$ and SB-242084. $c$ The interactions between 5-HT $2 A$ and SB-242084. $d$ The interactions between 5-HT 10 and SB242084. The binding affinity between $5-\mathrm{HT}_{1 \mathrm{D}}$ and SB-242084 is $398.11 \mathrm{nM}$, while the binding affinity between SB-242084 and 5-HT $2 \mathrm{C}$ is only 1 nM. 5-HT 5-hydroxytryptamine

the binding affinities of SB-242084 [60] to these four receptors are extremely different. The binding affinity between $5-\mathrm{HT}_{1 \mathrm{D}}$ and SB242084 is $398.11 \mathrm{nM}$ (Table 2), whereas the binding affinity between SB-242084 and $5-\mathrm{HT}_{2 \mathrm{C}}$ is $1 \mathrm{nM}$ (Table 2). Subtle differences were observed in the binding pockets of these four receptors, resulting in SB-242084 having different detailed interactions with $5-\mathrm{HT}_{2 \mathrm{~A}}, 5-\mathrm{HT}_{2 \mathrm{~B}}, 5-\mathrm{HT}_{2 \mathrm{C}}$, and $5-\mathrm{HT}_{1 \mathrm{D}}$.

Fig. 5 illustrates the interaction between SB-242084 and these four 5-HT receptors. When docking SB-242084 to the receptor subtypes, the amino group of SB-242084 formed a hydrogen bond with residues in these receptors with different distances: Asp134 $4^{3.32}(\sim 2.6 \AA)$ and Tyr358 $7.42(\sim 3.0 \AA)$ in 5-HT 2 ; Asp135 3.32

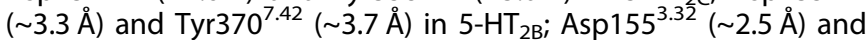
Tyr370 $7.42(\sim 2.9 \AA)$ in $5-\mathrm{HT}_{2 \mathrm{~A}} ;$ and Asp118 $8^{3.32}$ ( 3.1 $\AA$ ) and $\operatorname{Tyr}_{346^{7.42}}(\sim 3.7 \AA)$ in 5-HT $1 \mathrm{D}$. In addition to the common hydrogen bond mentioned above, the nitrogen atom on the pyridine ring of SB-242084 also formed hydrogen bonds with Asp134 $4^{3.32}(\sim 2.5 \AA)$ and $\operatorname{Ser} 138^{3.36}(\sim 3.3 \AA)$ in the binding pocket of $5-\mathrm{HT}_{2 \mathrm{C}}$. This resulted in a total of four hydrogen bonds, making the binding pocket of $5-\mathrm{HT}_{2 \mathrm{C}}$ the most selective toward SB-242084. In addition to the hydrogen bonds, two residues Val354.38 ( 3.8 $)$ ) and Val135 $5^{3.33}(\sim 4.1 \AA)$ contributed to the strong hydrophobic interaction in $5-\mathrm{HT}_{2 \mathrm{C}}$. In the binding pocket of $5-\mathrm{HT}_{2 \mathrm{~B}}$, one additional hydrogen bond between the nitrogen in terminal pyridine ring and Asn $344^{6.55}$ ( 4.3 $\AA$ ) was observed. SB-242084 can also form hydrophobic interactions with Val136 $6^{3.33}(\sim 3.5 \AA)$, Val366 7.38 $(\sim 3.9 \AA)$, and Phe $217^{5.39}(\sim 4.0 \AA)$ in $5-\mathrm{HT}_{2 \mathrm{~B}}$. In the binding pocket of $5-\mathrm{HT}_{2 \mathrm{~A}}$ and $5-\mathrm{HT}_{1 \mathrm{D}}$, there were only two common hydrogen bonds noted above, leading to the lower affinity. For $5-\mathrm{HT}_{2 \mathrm{~A}}$, we observed four hydrophobic interactions between SB-242084 and the key residues $\left(\sim 3.7 \AA\right.$ and $\sim 4.1 \AA$ with Val156 $6^{3.33}, \sim 3.6 \AA$ with Val366 ${ }^{7.38}$, and $\sim 4.1 \AA$ with Ser242 $\left.2^{5.46}\right)$, which was more than for 5$\mathrm{HT}_{1 \mathrm{D}}\left(\sim 3.9 \AA\right.$ with $\mathrm{Thr} 342^{7.38}, \sim 3.4 \AA$ with $\| \mathrm{le} 119^{3.33}$, and $\sim 3.8 \AA$ with Ala $\left.205^{5.46}\right)$.

5- $\mathrm{HT}_{2 \mathrm{~A}}$ and $5-\mathrm{HT}_{6}$ receptor subtypes bound with selective $5-\mathrm{HT}_{6}$ receptor agonist RO63-0563

As shown in Fig. 6 , the binding pocket of $5-\mathrm{HT}_{2 \mathrm{~A}} / 5-\mathrm{HT}_{6}$ was mainly composed of TM3, TM5, TM6, and TM7 (Table 1). Similar key residues were observed in the binding pockets, including Asp155/Asp106 ${ }^{3.32}$, Val156/Val107 ${ }^{3.33}$, Phe234/Phe188 ${ }^{5.39}$, Val235/ Val1895.40, Phe339/Phe284 ${ }^{6.51}$, Phe340/Phe285 ${ }^{6.52}$, 'Asn343/ Asn288 6.55 , and Tyr370/Tyr310 $0^{7.42}$. The binding affinity between $5-\mathrm{HT}_{2 \mathrm{~A}}$ and $\mathrm{RO} 63-0563$ [61] was reported to be larger than 10,000 nM (Table 2), whereas the binding affinity between R063-0563 and $5-\mathrm{HT}_{6}$ was $12.3 \mathrm{nM}$ (Table 2). Molecular docking was 


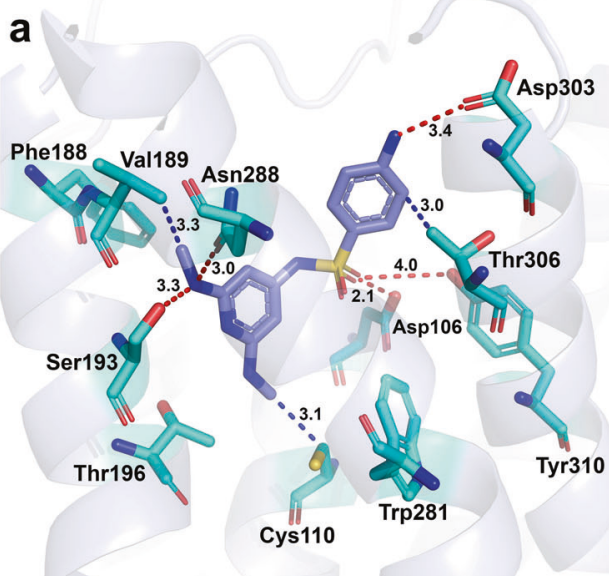

5-HT6/RO63-0563

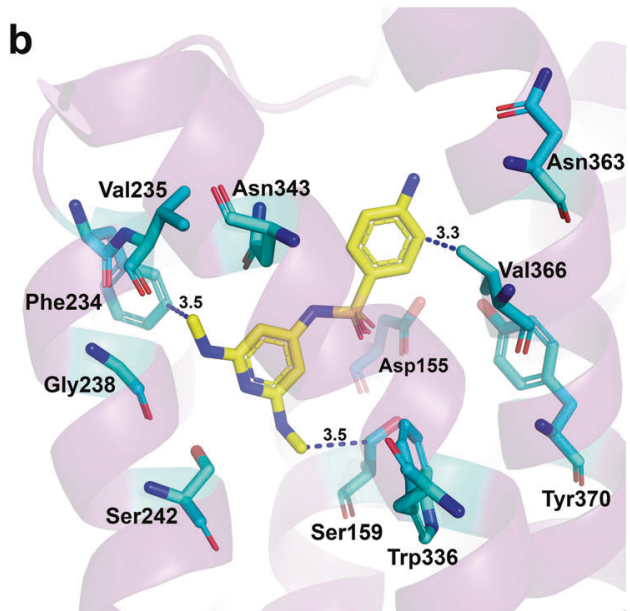

5-HT2A/RO63-0563

Fig. 6 The interaction between $\mathrm{RO} 63-0563$ and $5-\mathrm{HT}_{6}$ and $5-\mathrm{HT}_{2 \mathrm{~A}}$. a The interactions between 5- $\mathrm{HT}$ and $\mathrm{RO} 63-0563$. b The interactions between $5-\mathrm{HT}_{2 \mathrm{~A}}$ and $\mathrm{RO} 63-0563$. The binding affinity between $\mathrm{RO} 63-0563$ and $5-\mathrm{HT}_{6}$ is $12.3 \mathrm{nM}$, while the binding affinity between $5-\mathrm{HT}_{2 \mathrm{~A}}$ and RO63-0563 is larger than 10,000 nM. 5-HT 5-hydroxytryptamine

performed to explore the binding affinity, considering the number and distance of hydrophilic and hydrophobic interactions between RO63-0563 and these two 5-HT receptors.

Fig. 6 shows the selective $5-\mathrm{HT}_{6}$ receptor agonist R063-0563 binding with two different $5-\mathrm{HT}$ subtypes, the $5-\mathrm{HT}_{2 \mathrm{~A}}$, and $5-\mathrm{HT}_{6}$ receptors. When $\mathrm{RO} 63-0563$ is bound to $5-\mathrm{HT}_{6}$ receptor, the secondary amines on the pyridine ring form hydrogen bonds with the $\operatorname{Ser} 193^{5.43}(\sim 3.3 \AA)$ and $A s n 288^{6.55}(\sim 3.0 \AA)$; Asp303 $3^{7.35}$ forms a hydrogen bond with the primary amino groups on the phenyl ring ( $\sim 3.4 \AA \AA)$; the oxygen atom on sulfonyl forms hydrogen bonds with Asp106 $6^{3.32}(\sim 2.1 \AA)$ and Tyr310 $7.42(\sim 4.0 \AA)$; and the phenyl ring forms a hydrophobic interaction with Thr306 ${ }^{7.38}$ ( 3.0 ̊). RO630563 can also interact with Val189.40 $(\sim 3.3 \AA)$ and Cys $110^{3.36}$ $(\sim 3.1 \AA)$ via hydrophobic interactions. When binding R063-0563 to $5-\mathrm{HT}_{2 \mathrm{~A}}$, the $5-\mathrm{HT}_{2 \mathrm{~A}}$ receptor can only interact with Phe234.39 $(\sim 3.5 \AA)$, Ser159 $9^{3.36}(\sim 3.5 \AA)$, and Val366 $6^{7.38}(\sim 3.3 \AA)$ in a hydrophobic manner, which agrees with the data from the literature. No strong hydrogen bond was observed between RO63-0563 and $5-\mathrm{HT}_{2 \mathrm{~A}}$, resulting in $\mathrm{RO63-0563}$ having a significantly higher binding affinity to $5-\mathrm{HT}_{6}$ than $5-\mathrm{HT}_{2 \mathrm{~A}}$.

5- $\mathrm{HT}_{7}, 5-\mathrm{HT}_{2 \mathrm{~A}}, 5-\mathrm{HT}_{2 \mathrm{~B}}$, and 5- $\mathrm{HT}_{1 \mathrm{D}}$ receptor subtypes bound with selective $5-\mathrm{HT}_{7}$ receptor agonist $\mathrm{SB}-656104$

As shown in Table 1, similar key residues comprise the binding pocket of $5-\mathrm{HT}_{1 \mathrm{D}} / 5-\mathrm{HT}_{2 \mathrm{~A}} / 5-\mathrm{HT}_{2 \mathrm{~B}} / 5-\mathrm{HT}_{7}$ receptors, including Asp118/Asp155/Asp135/Asp162 ${ }^{3.32}$, Phe317/Phe339/Phe340/ Phe3436.51, Phe318/Phe340/Phe341/Phe344 ${ }^{6.52}$, and Tyr346/ Tyr370/Tyr370/Tyr374 ${ }^{7.42}$. SB-656104 [62] has higher selectivity towards the $5-\mathrm{HT}_{7}$ receptor than the other three receptors. The affinity between SB-656104 and $5-\mathrm{HT}_{7}$ is $2.0 \mathrm{nM}$ (Table 2), which is stronger than the affinity for $5-\mathrm{HT}_{1 \mathrm{D}}(25.12 \mathrm{nM}$, Table 2$), 5-\mathrm{HT}_{2 \mathrm{~A}}$ (63.10 nM, Table 2) and 5- $\mathrm{HT}_{2 \mathrm{~B}}(91.20 \mathrm{nM}$, Table 2). Observation of the detailed molecular interaction was made using molecular docking to provide an explanation for this phenomenon.

As shown in Fig. 7, the interactions between SB-656104 and the $5-\mathrm{HT}_{1 \mathrm{D}}, 5-\mathrm{HT}_{2 \mathrm{~A}}, 5-\mathrm{HT}_{2 \mathrm{~B}}$, and $5-\mathrm{HT}_{7}$ receptors differed subtly but distinctly. When docking SB-656104 to the $5-\mathrm{HT}_{7}$ receptor, the nitrogen atom on the piperidine ring formed a hydrogen bond with one of the oxygen atoms on the carboxyl of Asp162 $2^{3.32}(\sim 3.5$ $\AA)$; the hydroxyl of Ser $243^{5.43}(\sim 2.7 \AA)$ and Tyr230 5.30 ( $3.8 \AA$ ) formed hydrogen bonds with oxygen atoms on the sulfonyl group of SB-656104; the nitrogen atom of $\operatorname{Arg} 367^{7.35}(\sim 3.0 \AA)$ formed a hydrogen bond with the oxygen atom (ether bond) connecting the benzene ring and piperidine; and the nitrogen of indole in SB-
656104 can form a hydrogen bond with the Val163 $3^{3.33}$ ( 3.4 $\AA$ ). SB656104 formed hydrophobic interactions with Ala247 ${ }^{5.46}(\sim 4.0 \AA)$, Cys $166^{3.36}(\sim 3.1 \AA)$, sTrp340 ${ }^{6.48}(\sim 3.4 \AA)$, and Val163 $3^{3.33}(\sim 3.9 \AA)$. SB656104 formed five hydrogen bonds and four important hydrophobic bonds with $5-\mathrm{HT}_{7}$, which is consistent with its higher affinity.

In the binding pocket of $5-\mathrm{HT}_{1 \mathrm{D}}$, the formation of two hydrogen bonds was observed when binding with SB-656104. One hydrogen bond formed between the oxygen atoms on the sulfonyl group of SB-656104 and Ser201 ${ }^{5.43}(\sim 3.0 \AA)$ and the other hydrogen bond was observed between the five-membered ring and $\operatorname{Ser} 324^{6.58}(\sim 4.1 \AA)$. SB-656104 also formed several hydrophobic interactions with Thr198 $5.40(\sim 3.3 \AA)$, Cys122 $2^{3.36}(\sim 3.4 \AA)$, and $\operatorname{Trp} 314^{6.48}(\sim 3.7 \AA)$.

In the binding pocket of $5-\mathrm{HT}_{2 \mathrm{~A}}$, one hydrogen bond formed between the carboxyl group of $A s p 155^{3.32}(\sim 3.4 \AA)$ and the nitrogen atom on the piperidine. In addition, SB-656104 formed hydrophobic interactions with Val235 $5^{5.40}(\sim 3.4 \AA)$, Val366 7.38 $(\sim 3.5 \AA)$, Val156 $6^{3.33}(\sim 3.7 \AA ̊ \AA), \operatorname{Ser} 159^{3.36}(\sim 3.2 \AA)$, and $\operatorname{Trp} 336^{6.48}$ $(\sim 3.4 \AA)$. In the binding pocket of $5-\mathrm{HT}_{2 \mathrm{~B}}$, one hydrogen bond formed between the nitrogen in the indole and Val136 $36^{3.33}(\sim 3.0 \AA)$. In addition, five hydrophilic interactions with Val136 $6^{3.33}(\sim 3.5 \AA)$,

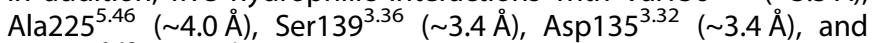
$\operatorname{Trp} 337^{6.48}(\sim 3.0 \AA)$ are shown in Fig. 7. Considering the same number of hydrogen bonds and hydrophobic bonds with different bond distances, the binding affinity of SB-656104 and $5-\mathrm{HT}_{2 \mathrm{~A}}$ is only slightly greater than that of $5-\mathrm{HT}_{2 \mathrm{~B}}$.

MD simulation between 5-HT receptors and ligands

To verify the proposed interactions and investigate the dynamic interactions, we carried out $50 \mathrm{~ns} \mathrm{MD}$ simulations for six $5-\mathrm{HT}$ receptors, $5-\mathrm{HT}_{1 \mathrm{~A}}, 5-\mathrm{HT}_{1 \mathrm{~B}}, 5-\mathrm{HT}_{2 \mathrm{~B}}, 5-\mathrm{HT}_{2} \mathrm{C}, 5-\mathrm{HT}_{6}$, and $5-\mathrm{HT}_{7}$, and their specific inhibitors.

For the $5-\mathrm{HT}_{1 \mathrm{~A}} / \mathrm{NAD}-299,5-\mathrm{HT}_{2 \mathrm{~B}} / \mathrm{BF}-1,5-\mathrm{HT}_{2} \mathrm{C} / \mathrm{SB}-24208$, and $5-$ $\mathrm{HT}_{7} / \mathrm{SB}-656104$ system, the root mean square deviation (RMSD) of the receptors and inhibitors fluctuated approximately $2.8 \AA, 1.9 \AA$, 1.4 $\AA$, 1.8 $\AA$ (black line in Fig. 8) and $1.8 \AA$, 1.8 $\AA$, $0.8 \AA$, $2.6 \AA$ (red line in Fig. 8) from $0 \mathrm{~ns}$ to $50 \mathrm{~ns}$, respectively, indicating these systems remain quite stable during the simulation. For the $5-\mathrm{HT}_{1 \mathrm{~B}} / \mathrm{SB}-236057$ complex, the RMSD of the protein slowly increased from $\sim 1.4 \AA$ at $0 \mathrm{~ns}$ to $\sim 3.0 \AA$ at $13 \mathrm{~ns}$, then remained stable for the rest of simulation (black line in Fig. 8b); the RMSD of SB-236057 fluctuated around $\sim 1.3 \AA$ from 0 ns to 50 ns. For the 5$\mathrm{HT}_{6} / \mathrm{RO} 63-0563$ system, the RMSD of $5-\mathrm{HT}_{6}$ fluctuated 

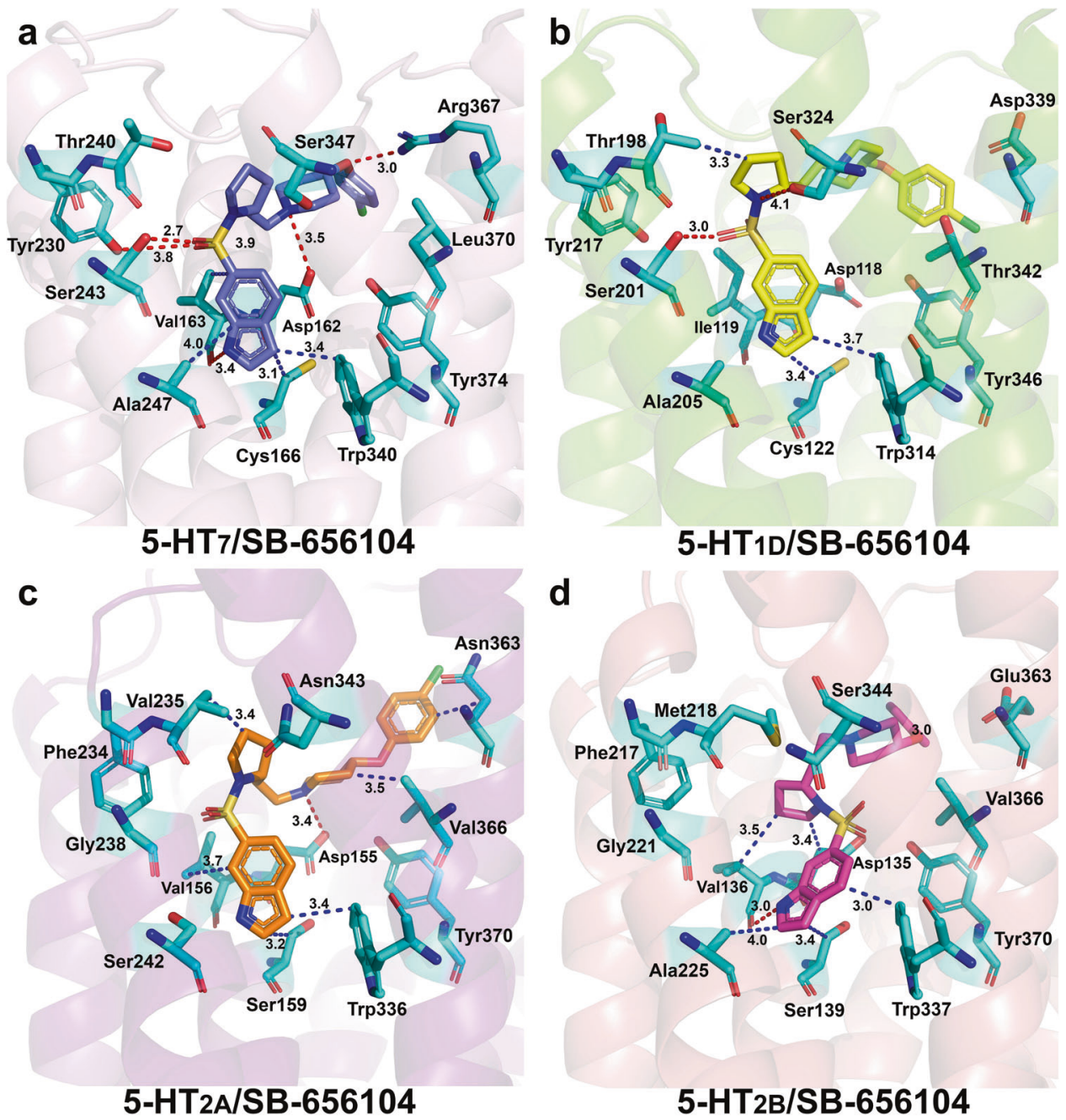

Fig. 7 The interaction between SB-656104 and 5- $\mathrm{HT}_{7}, 5-\mathrm{HT}_{1 \mathrm{D}}, 5-\mathrm{HT}_{2 \mathrm{~A}}$, and 5- $\mathrm{HT}_{2 \mathrm{~B}}$. a The interactions between 5-HT 7 and SB-656104. b The interactions between 5- $\mathrm{HT}_{1 \mathrm{D}}$ and $\mathrm{SB}-656104$. c The interactions between 5- $\mathrm{HT}_{2 \mathrm{~A}}$ and $\mathrm{SB}-656104$. d The interactions between 5- $\mathrm{HT} \mathrm{T}_{2 \mathrm{~B}}$ and $\mathrm{SB}-$ 656104. The affinity of SB-656104 with $5-\mathrm{HT}_{7}$ is $2.0 \mathrm{nM}$, which is less than the affinity with $5-\mathrm{HT}_{1 \mathrm{D}}(25.12 \mathrm{nM}), 5-\mathrm{HT}_{2 \mathrm{~A}}(63.10 \mathrm{nM})$, and $5-\mathrm{HT}_{2 \mathrm{~B}}$ $(91.20 \mathrm{nM})$

approximately $1.8 \AA$ and the RMSD of RO53-0563 increased from $\sim 2.0 \AA$ at 0 ns to $\sim 2.4 \AA$ at $12 \mathrm{~ns}$, then sharply decreased to $\sim 2.1 \AA$ and fluctuated around that value for the remainder of the simulation.

All systems remained in a stable conformation for more than $30 \mathrm{~ns}$, so 300 snapshots were extracted from $20 \mathrm{~ns}$ to $50 \mathrm{~ns}$ and used to calculate the mean binding energy. According to the binding energy of key residues, we determined the most important key residues and their contributions to receptor-ligand interactions. The residues at positions 3.32 and 3.33 (Table 1) in the third alpha helix significantly contribute to receptor-ligand binding in all systems except $5-\mathrm{HT}_{6} / \mathrm{RO} 63-0563$ (Fig. 9e and Supplementary Table S5) due to their ability to form strong hydrogen bonds. In particular, Asp134.32 (-8.868 kcal/mol, Supplementary Table S4) in $5-\mathrm{HT}_{2 \mathrm{C}}$ and Asp162 $2^{3.32}$ in $5-\mathrm{HT}_{7}(-6.793 \mathrm{kcal} / \mathrm{mol}$, Supplementary Table S6) greatly contributed to the total binding of $5-\mathrm{HT}_{2 \mathrm{C}} / \mathrm{SB}-$ 242084 and $5-\mathrm{HT}_{7} / \mathrm{SB}-656104$ due to their strong electrostatic interactions $(-11.362 \mathrm{kcal} / \mathrm{mol} /-10.807 \mathrm{kcal} / \mathrm{mol}$, Supplementary Table S4/S6). Val $117^{3.33}(-0.906 \mathrm{kcal} / \mathrm{mol}$, Supplementary Table S1) in $5-\mathrm{HT}_{1 \mathrm{~A}}, \| l \mathrm{le} 130^{3.33}(-4.934 \mathrm{kcal} / \mathrm{mol}$, Supplementary Table S2) in $5-\mathrm{HT}_{1 \mathrm{~B}}, \mathrm{Val} 136^{3.33}(-3.884 \mathrm{kcal} / \mathrm{mol}$, Supplementary Table S3) in $5-\mathrm{HT}_{2 \mathrm{~B}}$, Val135 $5^{3.33}(-3.181 \mathrm{kcal} / \mathrm{mol}$, Supplementary Table S4) in $5-\mathrm{HT}_{2 \mathrm{C}}$, and Val163 $3^{3.33}(-4.216 \mathrm{kcal} / \mathrm{mol}$, Supplementary Table S6) in $5-\mathrm{HT}_{7}$ greatly contributed to the binding of ligands in these residues. Interestingly, the binding between $5-\mathrm{HT}_{6}$ and $\mathrm{RO} 63-0563$ (Fig. 9e) was mainly a result of residue Asp303 3.35 (total energy: $-8.921 \mathrm{kcal} / \mathrm{mol}$, Supplementary Table S5) owing to electrostatic interaction $(-9.033 \mathrm{kcal} / \mathrm{mol}$, Supplementary Table S5), and Asn $288^{6.55}$ (total energy: $-2.454 \mathrm{kcal} / \mathrm{mol}$, Supplementary Table S5) also contributed to the binding.

Moreover, we performed 50 ns MD simulations for six other 5$\mathrm{HT}$ receptors, 5- $\mathrm{HT}_{1 \mathrm{D}}, 5-\mathrm{HT}_{1 \mathrm{E}}, 5-\mathrm{HT}_{1 \mathrm{~F}}, 5-\mathrm{HT}_{2 \mathrm{~A}}, 5-\mathrm{HT}_{4}$, and $5-\mathrm{HT}_{5}$, and their specific ligands. Fig. 10a-f shows the RMSD of the receptors and ligands. Our MD results show that the systems remained stable during the MD simulation. The RMSDs of all the receptors and ligands were approximately $\sim 1.2 \AA$ to $2.8 \AA$. For these six systems, 300 snapshots were extracted from $20 \mathrm{~ns}$ to $50 \mathrm{~ns}$ and used to calculate the mean binding energy, and the results are shown in Fig. 11. The MD results correlate well with the docking results. For example, Ile $119^{3.33}$ and Ser $321^{6.55}$ in $5-\mathrm{HT}_{1 \mathrm{D}}$ greatly contributed to the binding of SB-236057; Asp103 $3^{3.32}$ and Ile $104^{3.33}$ were important in the recognition of SB-242084 in 5-HT $1 \mathrm{E}$; lle $104^{3.33}$, Phe $310^{6.52}$, and Glu313 $3^{6.55}$ in $5-\mathrm{HT}_{1 \mathrm{~F}}$ played key roles in the recognition of BF-1; Phe235 $5^{5.40}$, Phe340 6.52 , and Leu363.35 were important for BF-1 in $5-\mathrm{HT}_{2 \mathrm{~A}}$; Asp $100^{3.32}$, Val101 ${ }^{3.33}$, and Asn279 $9^{6.55}$ were the key residues for SB-656104 in $5-\mathrm{HT}_{4}$; and 

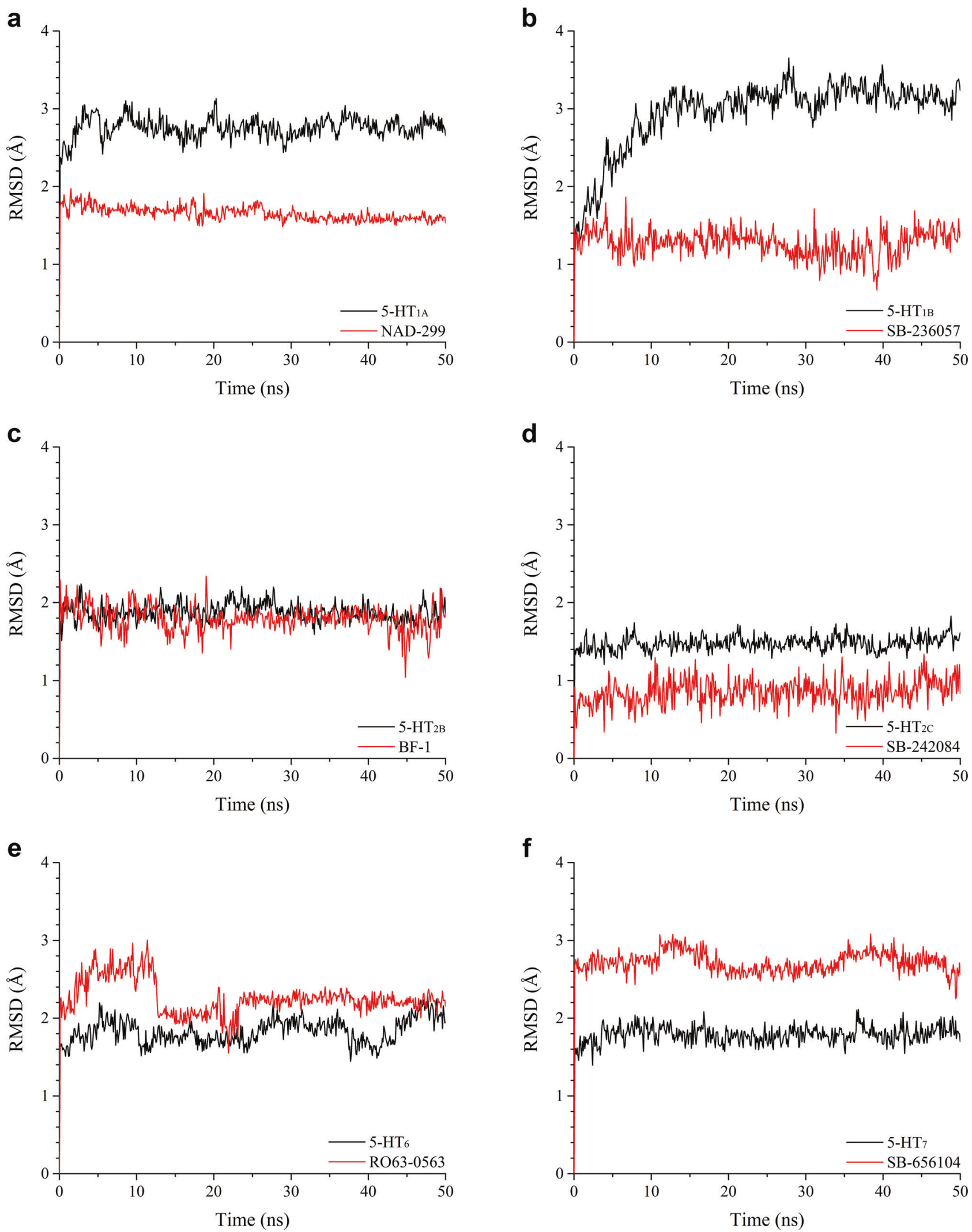

Fig. 8 The root mean square deviation (RMSD) of 5- $\mathrm{HT}\left(5-\mathrm{HT}_{1 \mathrm{~A}}, 5-\mathrm{HT}_{1 \mathrm{~B}}, 5-\mathrm{HT}_{2 \mathrm{~B}}, 5-\mathrm{HT}_{2 \mathrm{C}}, 5-\mathrm{HT}_{6}\right.$, and 5- $\left.\mathrm{HT}_{7}\right)$ receptors complexed with compound for 50 ns molecular dynamics (MD) simulation. a The RMSD of 5-HT ${ }_{1 A}$ and NAD-299. b The RMSD of 5-HT 1 and SB-236057. c The RMSD of $5-\mathrm{HT}_{2 \mathrm{~B}}$ and BF-1. d The RMSD of 5-HT $2 \mathrm{C}$ and SB-242084. e The RMSD of 5-HT 6 and RO63-0563. $f$ The RMSD of 5-HT 7 and SB-656104. All the systems are stable during the MD simulation. 5-HT 5-hydroxytryptamine 

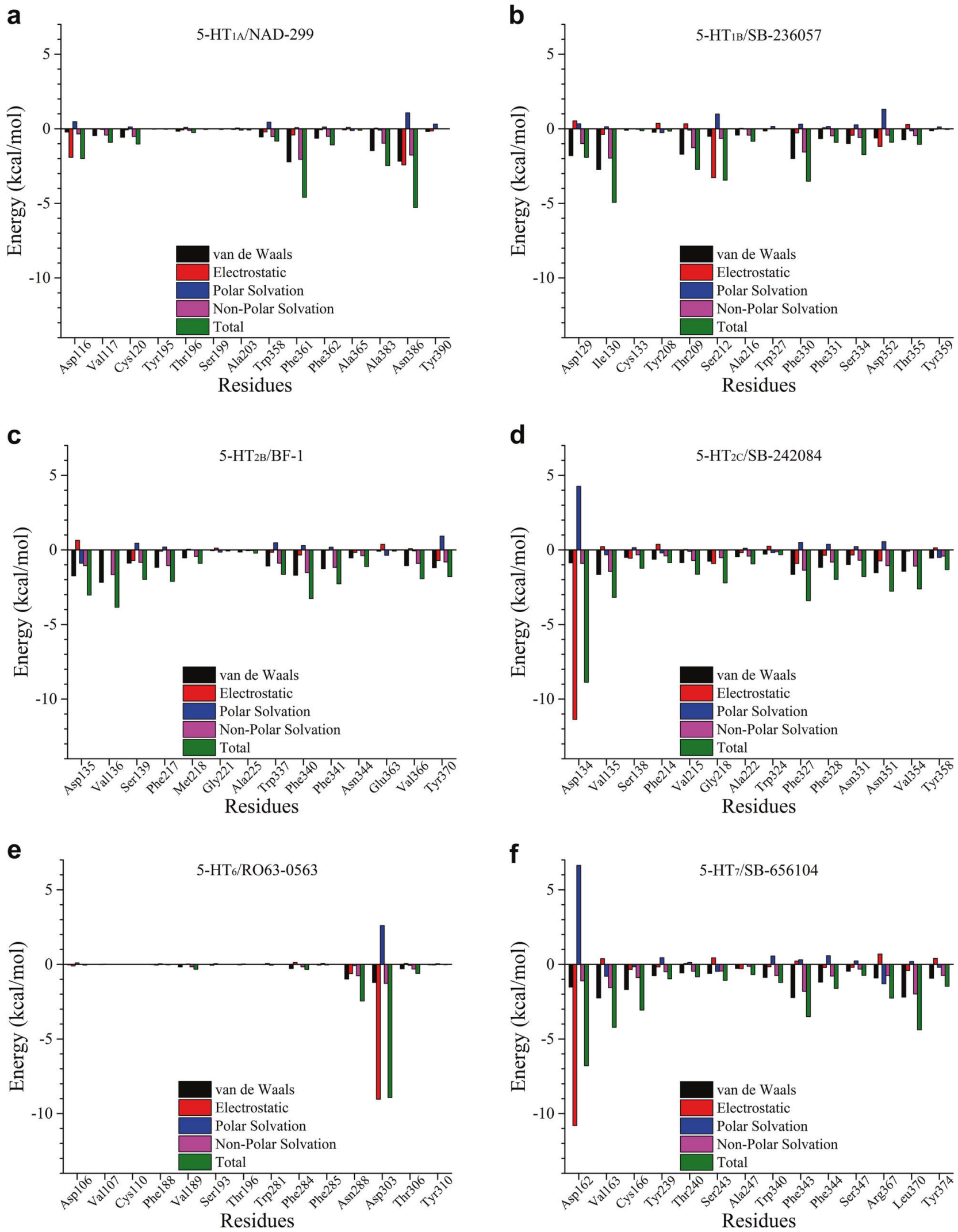

Fig. 9 Free energy decomposition of key residues for $5-\mathrm{HT}\left(5-\mathrm{HT}_{1 \mathrm{~A}}, 5-\mathrm{HT}_{1 \mathrm{~B}}, 5-\mathrm{HT}_{2 \mathrm{~B}}, 5-\mathrm{HT}_{2}, 5-\mathrm{HT}_{6}\right.$, and 5- $\left.\mathrm{HT}_{7}\right)$ receptors complexed with compounds during $50 \mathrm{~ns}$ molecular dynamics (MD) simulation. a The energy decomposition of key residues at 5-HT ${ }_{1 \mathrm{~A}}$. $\mathbf{b}$ The energy decomposition of key residues at $5-\mathrm{HT}_{1 \mathrm{~B}}$. c The energy decomposition of key residues at $5-\mathrm{HT}_{2 \mathrm{~B}}$. $\mathbf{d}$ The energy decomposition of key residues at $5-\mathrm{HT}_{2 \mathrm{C}}$. $\mathbf{e}$ The energy decomposition of key residues at $5-\mathrm{HT}_{6} . \mathbf{f}$ The energy decomposition of key residues at $5-\mathrm{HT}_{7}$. The contributions of key residues are consistent with our docking results. 5-HT 5-hydroxytryptamine 

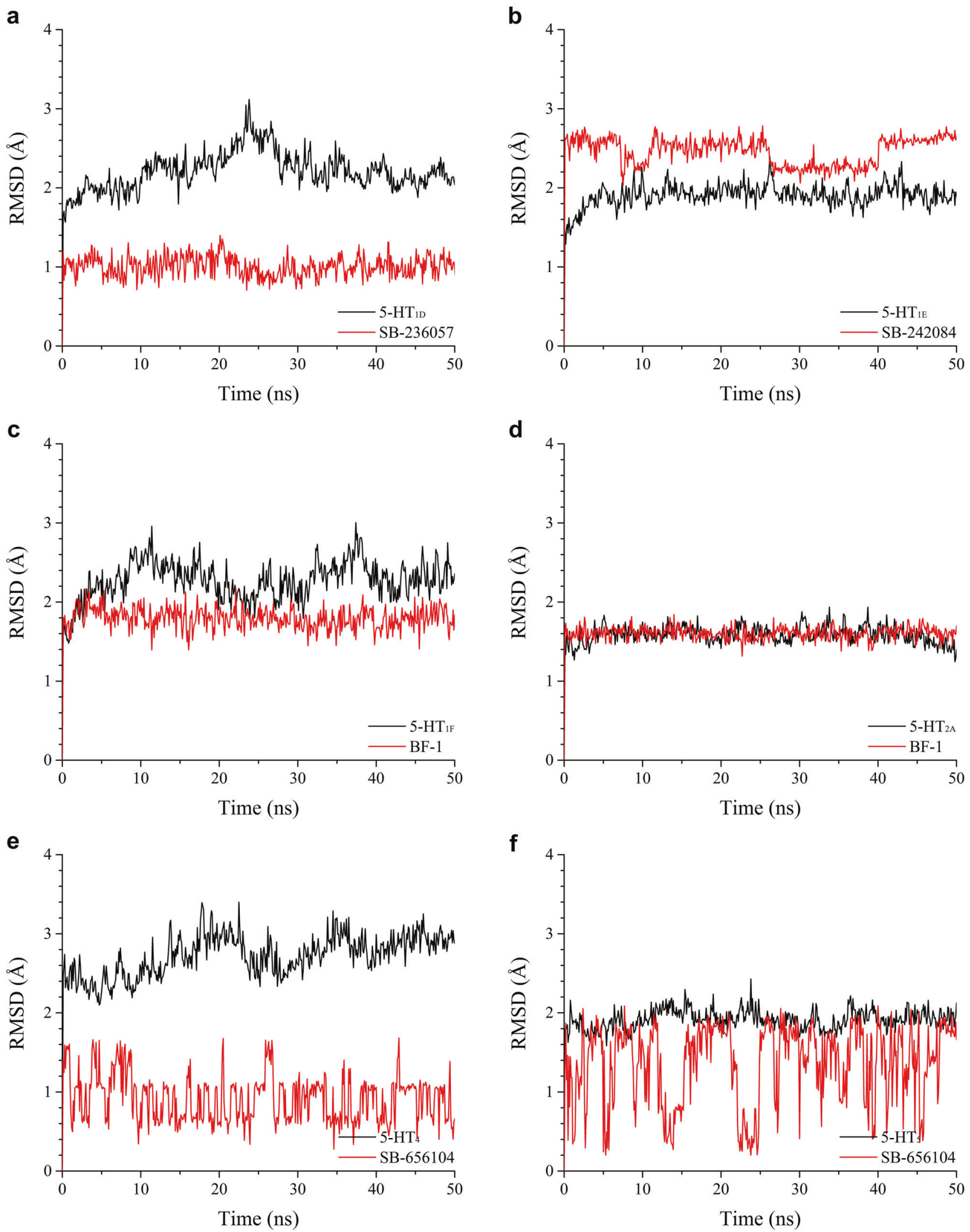

Fig. 10 The root mean square deviation (RMSD) of 5- $\mathrm{HT}\left(5-\mathrm{HT}_{1 \mathrm{D}}, 5-\mathrm{HT}_{1 \mathrm{E}}, 5-\mathrm{HT}_{1 \mathrm{~F}}, 5-\mathrm{HT}_{2 \mathrm{~A}}, 5-\mathrm{HT}_{4}\right.$, and 5- $\left.\mathrm{HT}_{5}\right)$ receptors complexed with compound for 50 ns molecular dynamics (MD) simulation. a The RMSD of 5-HT 1 and SB-236057. $\mathbf{b}$ The RMSD of 5-HT 1 and SB-242084. c The RMSD of $5-\mathrm{HT}_{1 \mathrm{~F}}$ and BF-1. d The RMSD of 5-HT $\mathrm{H}_{2 \mathrm{~A}}$ and BF-1. e The RMSD of 5-HT 4 and SB-656104. f The RMSD of 5-HT 5 and SB-656104. All the systems are stable during the MD simulation. 5-HT 5-hydroxytryptamine 
a

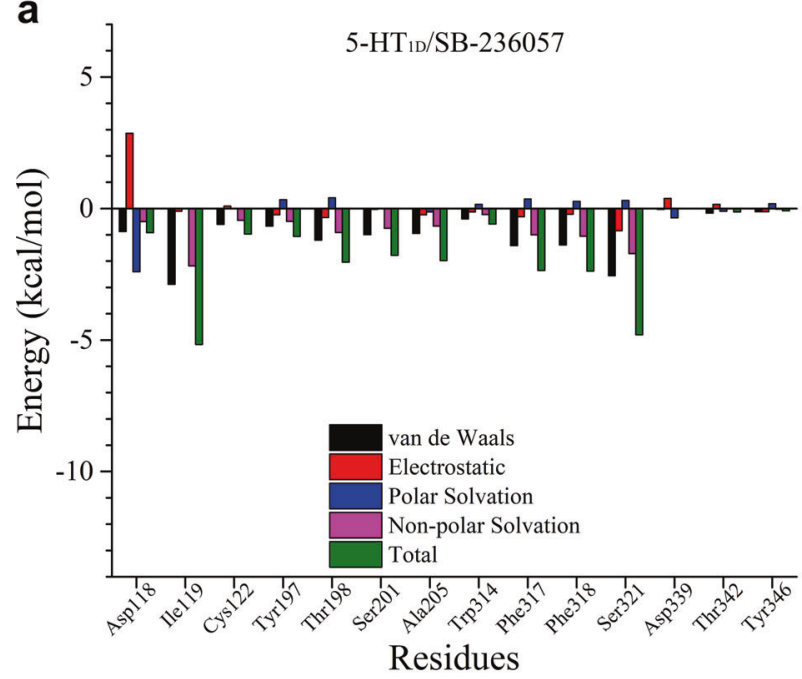

C

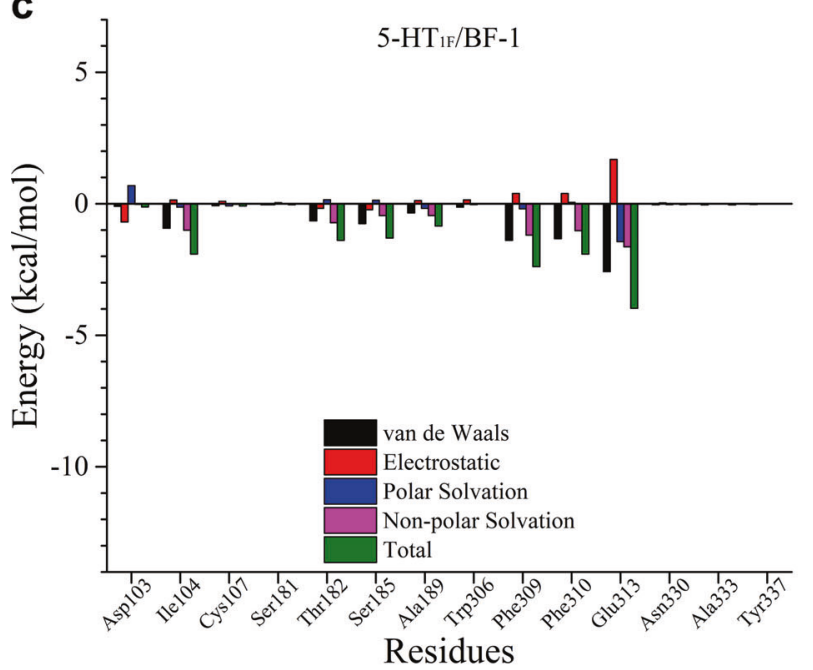

e

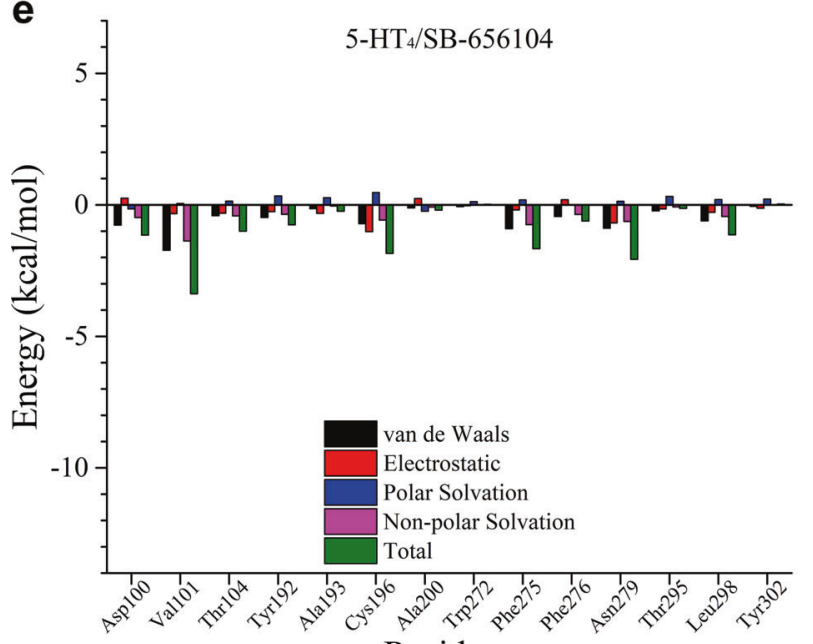

Residues b

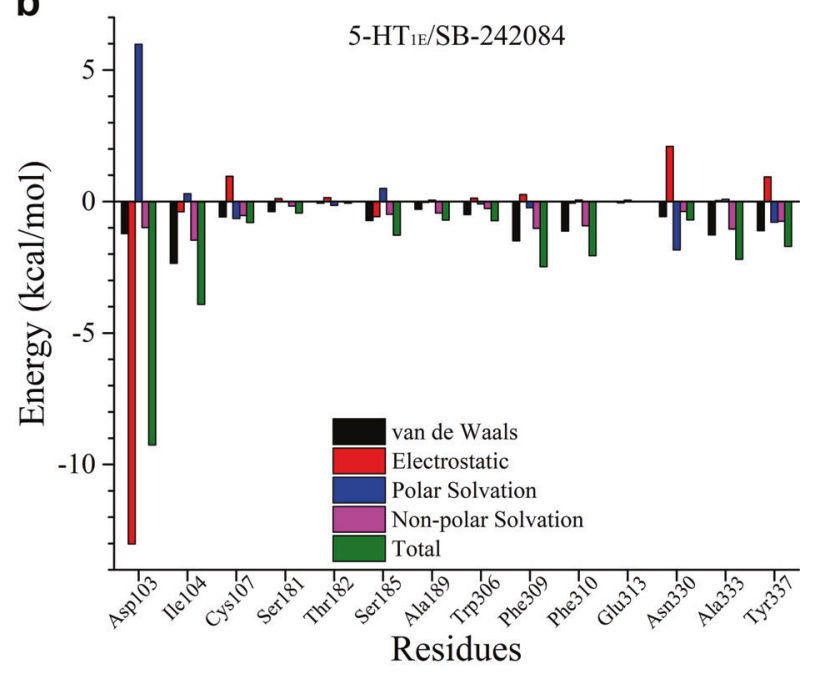

d

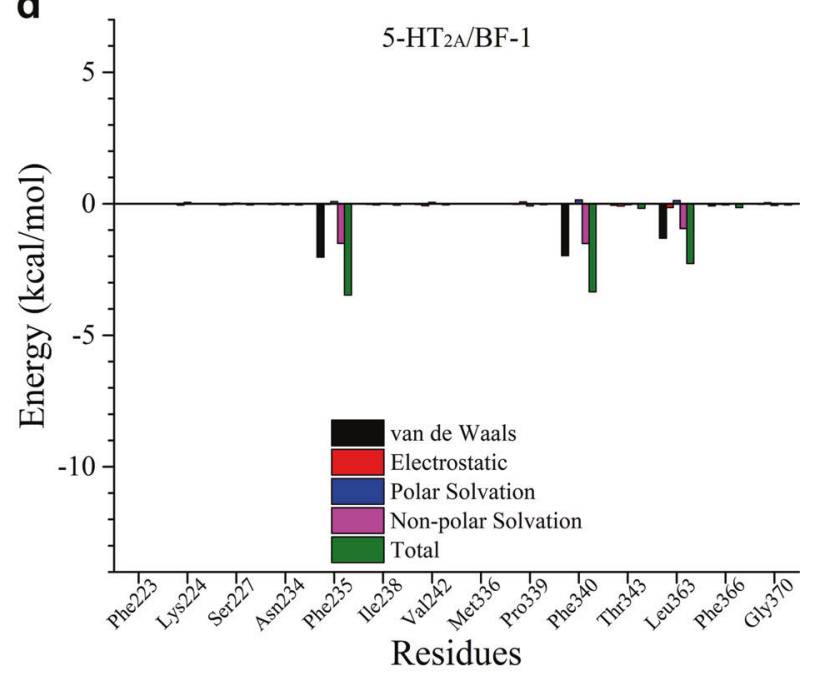

f

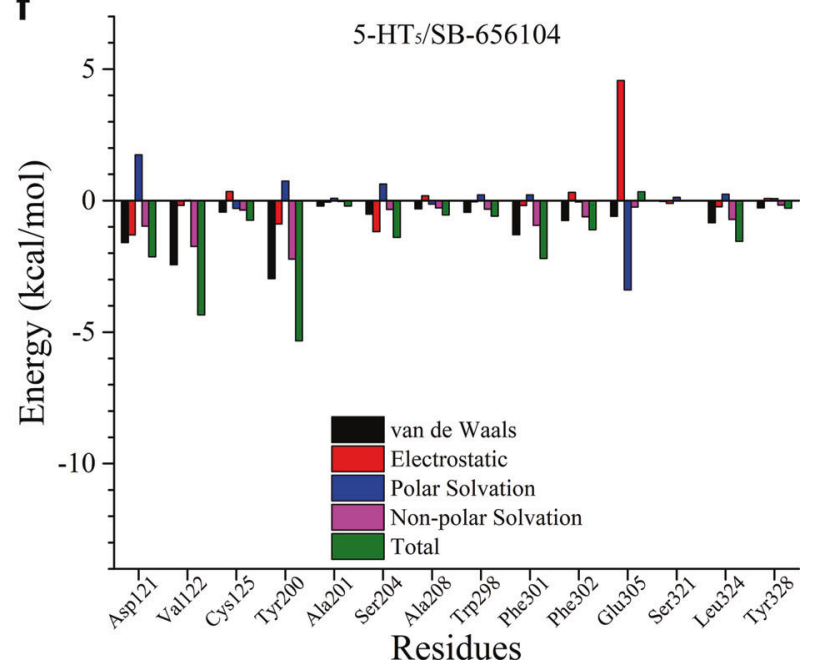

Fig. 11 Free energy decomposition of key residues for $5-\mathrm{HT}\left(5-\mathrm{HT}_{1 \mathrm{D}}, 5-\mathrm{HT}_{1 \mathrm{E}}, 5-\mathrm{HT}_{1 \mathrm{~F}}, 5-\mathrm{HT}_{2 \mathrm{~A}}, 5-\mathrm{HT}_{4}\right.$, and 5- $\left.\mathrm{HT}_{5}\right)$ receptors complexed with compounds during $50 \mathrm{~ns}$ molecular dynamics (MD) simulation. a The energy decompostion of key residues at 5-HT $1 \mathrm{D}$. $\mathbf{b}$ The energy decompostion of key residues at $5-\mathrm{HT}_{1 \mathrm{E}}$. $\mathbf{c}$ The energy decompostion of key residues at $5-\mathrm{HT}_{1 \mathrm{~F}}$. $\mathbf{d}$ The energy decompostion of key residues at $5-\mathrm{HT}_{2 \mathrm{~A}}$. e The energy decompostion of key residues at 5- $\mathrm{HT}_{4}$. $\mathbf{f}$ The energy decompostion of key residues at 5- $\mathrm{HT}_{5}$. The contributions of key residues are consistent with our docking results. 5-HT 5-hydroxytryptamine 
Adaboost Algorithm

With MACCS Fingerprint | Score: $\mathbf{5 . 1 5 2}$

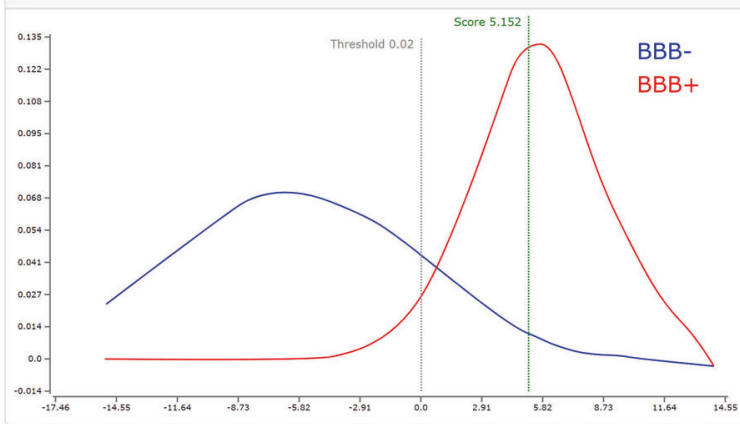

C With Molprint 2D Fingerprint | Score: $\mathbf{1 0 . 4 2 4}$

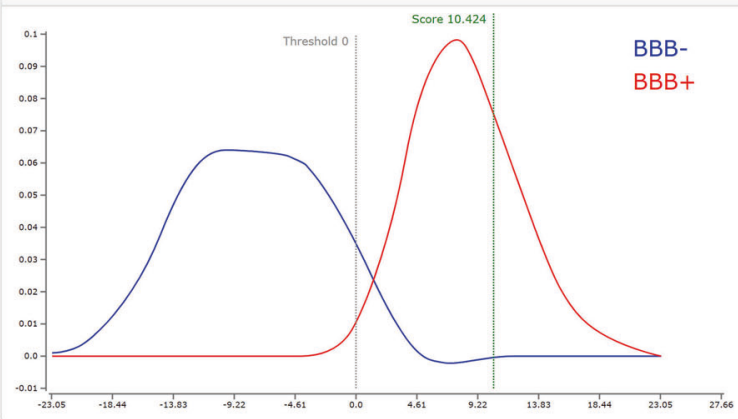

With PubChem Fingerprint | Score: $\mathbf{8 . 5 9 4}$

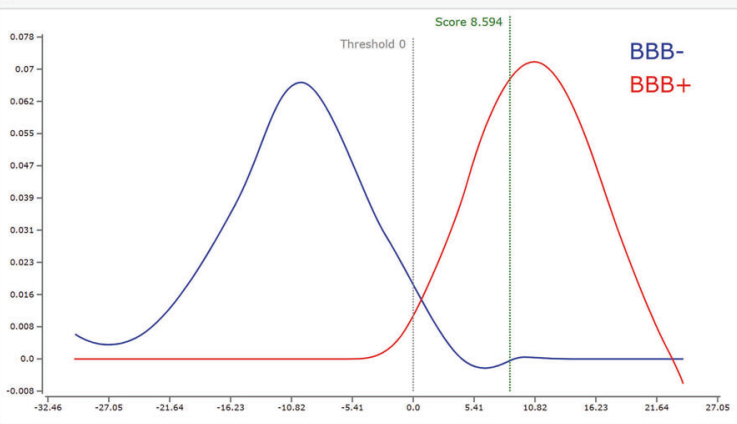

Q With FP2 Fingerprint | Score: $\mathbf{1 2 . 0 4 4}$

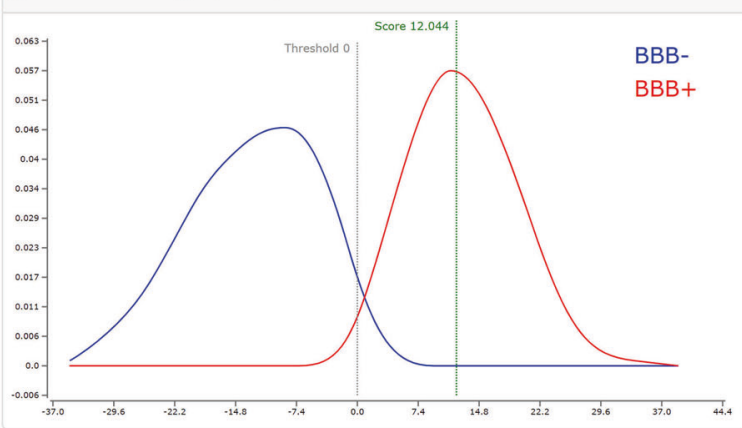

SVM Algorithm

Q With MACCS Fingerprint | Score: $\mathbf{0 . 0 8 3}$

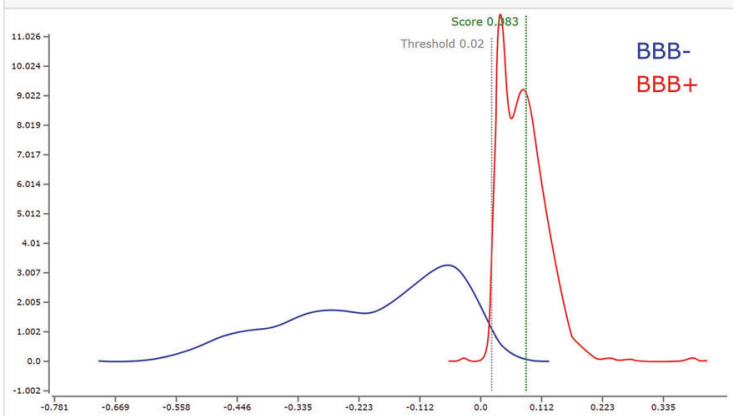

With Molprint 2D Fingerprint | Score: $\mathbf{0 . 3 5 9}$

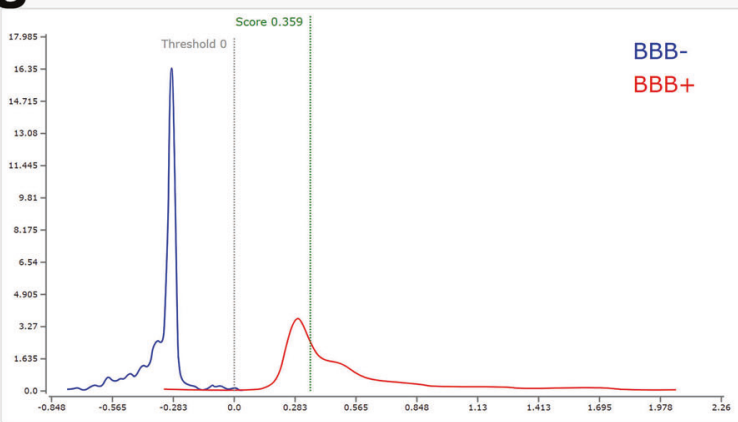

With PubChem Fingerprint | Score: $\mathbf{0 . 1 7 1}$

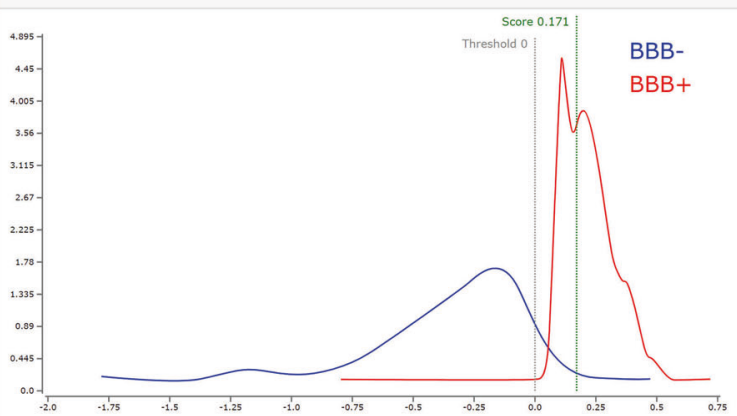

With FP2 Fingerprint | Score: $\mathbf{0 . 1 6}$

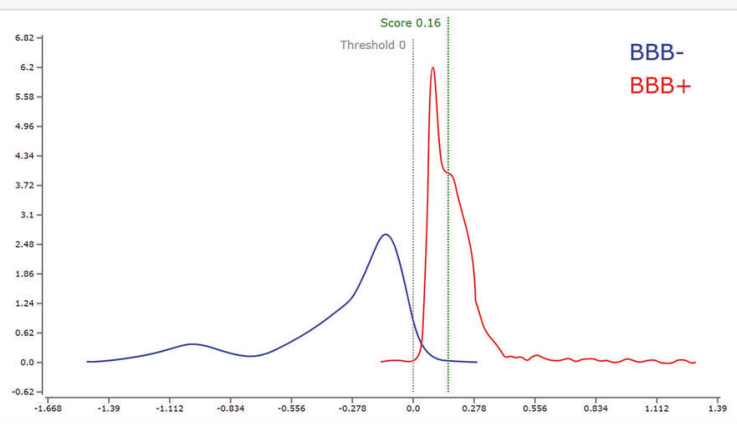

Fig. 12 Blood-brain barrier (BBB) prediction for Captagon using our established algorithms. a Adaboost algorithm with MACCS fingerprint. b Adaboost algorithm with PubChem fingerprint. c Adaboost algorithm with Molprint 2D fingerprint. d Adaboost algorithm with FP2 fingerprint. e SVM algorithm with MACCS fingerprint. f SVM algorithm with Pubchem fingerprint. $g$ SVM algorithm with Molprint 2D fingerprint. h SVM algorithm with FP2 fingerprint 

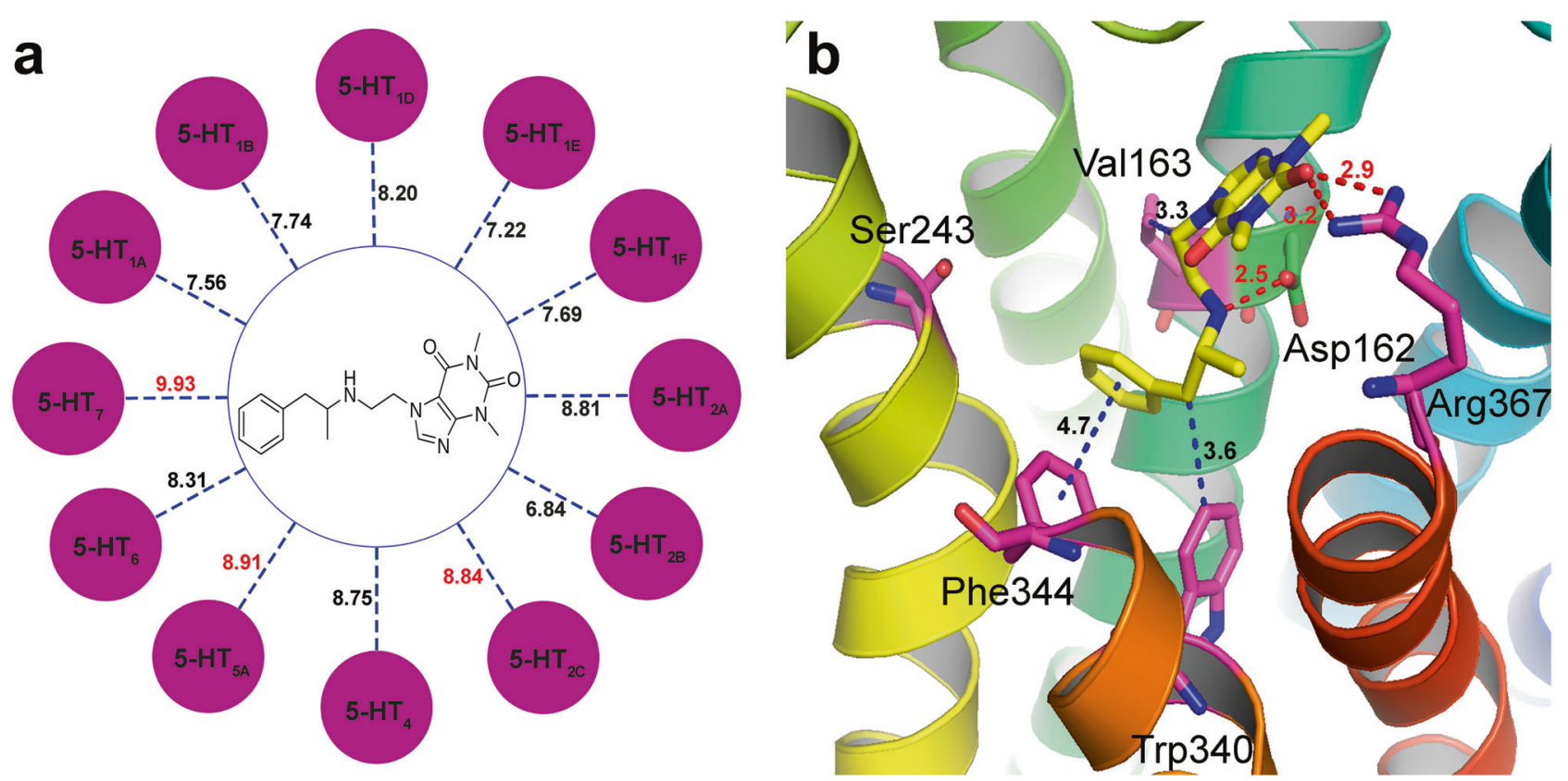

Fig. 13 Systems pharmacology analysis of Captagon and the predicted targets using our established hallucinogen knowledgebase and HTDocking target identification program. a Predicted targets/off-targets for Captagon. b The detailed interactions between Captagon and 5- $\mathrm{HT}_{7} .5-\mathrm{HT}_{2 \mathrm{c}}$ (docking score: 8.84), 5- $\mathrm{HT}_{5 \mathrm{a}}$ (docking score: 8.91), and 5- $\mathrm{HT}_{7}$ (docking score: 9.93) were the most promising targets for Captagon before metabolism

Asp $121^{3.32}$, Val122 3.33 , and Tyr200 ${ }^{5.39}$ played important roles for the binding of SB-656104 in $5-\mathrm{HT}_{5}$.

Systems pharmacology analysis of Captagon using our hallucinogen knowledgebase

Captagon, the trademark name for the synthetic stimulant fenethylline, is a CNS stimulator with stronger and longer-lasting effects on aggression, detachment, cognitive enhancement, and alertness than one of its main metabolites, amphetamine [63-68].

Captagon was first synthesized in 1961 and can be metabolized into amphetamine (24.5\% of oral dose) and theophylline $(13.7 \%$ of oral dose). Captagon was banned in most countries by the $1980 \mathrm{~s}$ due to its addictive properties and lack of medical use [63-68]. Captagon trafficking has been a big problem in the Middle East for many years. Between 2013 and the end of August 2016, Lebanon seized more than 70 million Captagon pills, worth \$14 billion, which accounts for only $10 \%$ of the total production. In May 2017, French authorities reported confiscating approximately 300 pounds of Captagon, seizing 750,000 pills worth an estimated $\$ 1.7$ million. In July 2018, Lebanon seized 3.7 million Captagon pills from Syria. Moreover, Captagon is demonized as a war drug: fighters on Captagon during combat may feel a sense of wellbeing, euphoria, and invincibility. It is clear that Captagon can be used to suppress pain and increase aggression in soldiers. The use of these drugs is not limited to soldiers and involves the civilian population in areas prevailing in hopelessness and helplessness.

First, we carried out the BBB prediction for Captagon. The BBB predictor was built by applying the SVM (Support Vector Machine) and LiCABEDS (Ligand Classifier of Adaptively Boosting Ensemble Decision Stumps) $[69,70]$ algorithms to four types of fingerprints (MACCS, PubChem, Molprint 2D, and FP2) of 1593 reported compounds [71]. Unity was used in our original publication and was replaced with PubChem Structure Fingerprint in a subsequent upgrade. The BBB predictor accepts a query compound with any given combination of algorithm and fingerprint as the input and predicts whether or not the query compound can move across the BBB to the central nervous system (CNS). In our scenario, the predictor was run eight times for all possible algorithm and fingerprint combinations. The results indicate that Captagon can move across the BBB to the CNS (as shown in Fig. 12).

Using our established knowledgebase and computational tools, we performed off-target prediction of Captagon with 5-HT receptors due to the lipophilicity of Captagon [72]. As shown in Fig. 13 (left), we mapped the prediction of these potential molecular targets of Captagon via the docking scores. Interesting, our results showed that most of the docking scores were higher than 7.0 due to the flexible structure of Captagon. Moreover, we suggest that $5-\mathrm{HT}_{2 \mathrm{c}}$ (docking score 8.84), 5- $\mathrm{HT}_{5 \mathrm{a}}$ (docking score 8.91), and $5-\mathrm{HT}_{7}$ (docking score 9.93) were the most promising targets for Captagon before metabolism. As an illustration of the detailed interactions between Captagon and 5- $\mathrm{HT}$ receptors, we explored the detailed docking pose of Captagon and $5-\mathrm{HT}_{7}$, as shown in Fig. 13 (right). Our docking results showed that Asp162 $2^{3.32}(2.5 \AA)$ and $\operatorname{Arg} 367^{7.35}(2.9-3.2 \AA)$ in $5-\mathrm{HT}_{7}$ formed strong hydrogen bonds with Captagon and several residues,

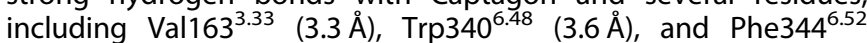
$(4.7 \AA)$, contributed to the hydrophobic or $\pi-\pi$ interactions.

To further validate the role of these residues, we carried out 50 ns MD simulations for $5-\mathrm{HT}_{7}$ complexed with Captagon. Fig. 14a shows that the RMSDs of Captagon and $5-\mathrm{HT}_{7}$ remained stable at $\sim 2.8 \AA$ and $1.9 \AA$ during the MD. The energy decomposition is shown in Fig. 14b. Our results show that Asp $162^{3.32}$ greatly contributed to the binding of Captagon, with electrostatic energy of $-3.75 \mathrm{kcal} / \mathrm{mol}$ and total energy of $-3.85 \mathrm{kcal} / \mathrm{mol}$. Moreover, the total energy contribution of Val $163^{3.33}$ and $A r g 367^{7.35}$ was $-3.3 \mathrm{kcal} / \mathrm{mol}$ and $-2.4 \mathrm{kcal} / \mathrm{mol}$. These results are consistent with our docking results, indicating Captagon may bind to $5-\mathrm{HT}_{7}$. Future experiments will be carried out to validate the interactions between Captagon and 5-HT receptors.

\section{DISCUSSION}

The residue at helix III position 32 (3.32) is a commonly conserved residue for the binding of GPCR receptors. In the present study, we 

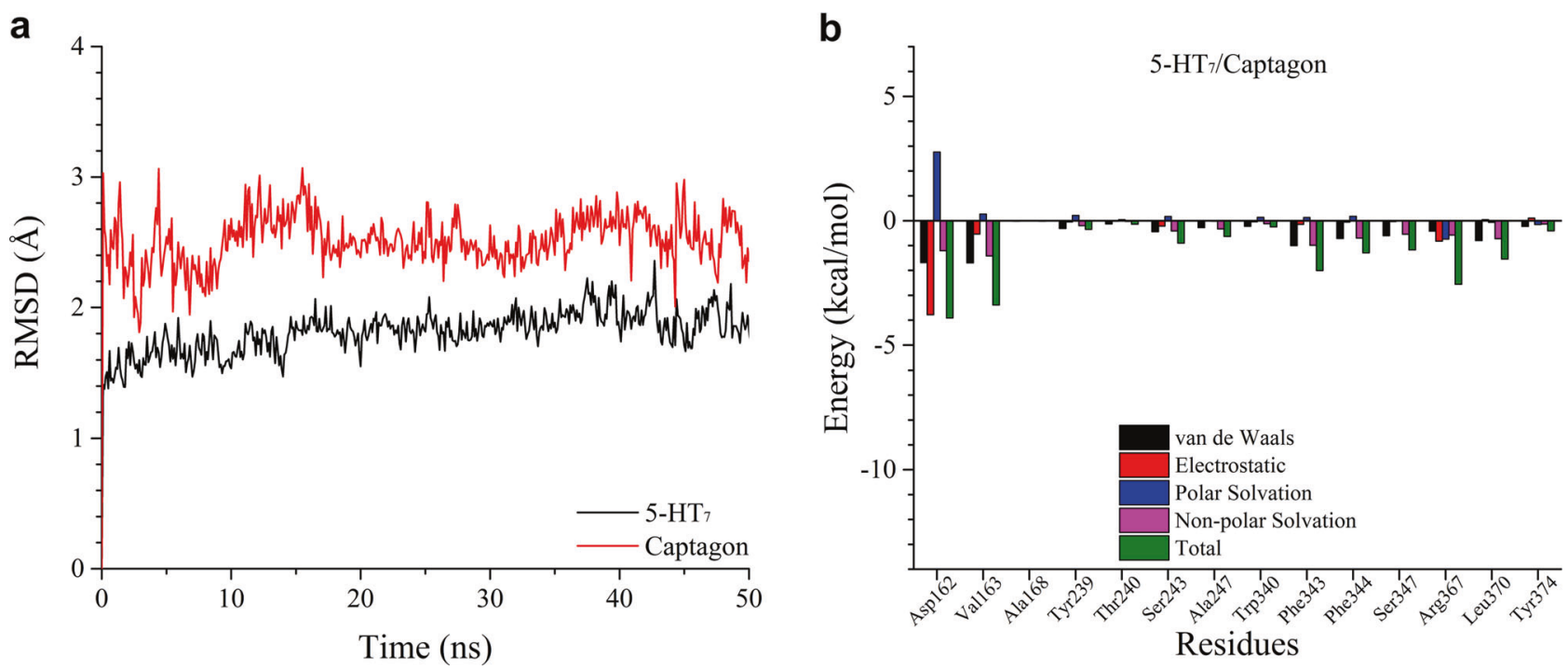

Fig. 14 The root mean square deviation (RMSD) and energy decomposition of $5-\mathrm{HT}_{7}$ and Captagon during $50 \mathrm{~ns}$ molecular dynamics (MD)

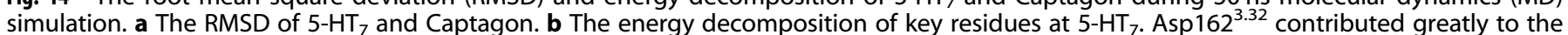
binding of Captagon, with $-8.2 \mathrm{kcal} / \mathrm{mol}$ for electrostatic and $-6.8 \mathrm{kcal} / \mathrm{mol}$ for the total energy. Moreover, the total energy of Val $163^{3.33}$ and Phe $344^{6.52}$ were $-3.5 \mathrm{kcal} / \mathrm{mol}$ and $-2.4 \mathrm{kcal} / \mathrm{mol}$. 5-HT 5-hydroxytryptamine

found that $\mathrm{Asp}^{3.32}$ at this position of the $5-\mathrm{HT}$ receptors greatly contributed to the formability of hydrogen bonds and the total binding energy, which is consistent with the literature. Moreover, $\operatorname{Trp}^{6.48}$, Phe ${ }^{6.51}$, and Phe ${ }^{6.52}$ at helix VI and $\mathrm{Tyr}^{7.42}$ at helix VII are conserved residues involved in the binding pocket of GPCR receptors. Our docking and MD results show the great energy contribution of these residues to the total binding energy between ligands and receptors. For example, phenylalanine residue $\left(\mathrm{Phe}^{6.51}\right.$ ) played a key role in the total binding energy in $5-\mathrm{HT}_{1 \mathrm{~A}}, 5-\mathrm{HT}_{1 \mathrm{~B}}, 5-\mathrm{HT}_{2 \mathrm{~B}}$, and $5-\mathrm{HT}_{2 \mathrm{C}}$, which is in line with the literature. $\mathrm{Tyr}^{7.42}$ interacted with small molecules inside the binding pockets of many $5-\mathrm{HT}$ receptor subtypes, including $5-\mathrm{HT}_{1 \mathrm{~A}}, 5-\mathrm{HT}_{1 \mathrm{D}}, 5-\mathrm{HT}_{2 \mathrm{~A}}, 5-\mathrm{HT}_{2 \mathrm{~B}}, 5-\mathrm{HT}_{2 \mathrm{C}}$, and $5-\mathrm{HT}_{6}$.

For selectivity, we found that Asn $386^{7.38}$ (bold, Table 1), a unique residue found in $5-\mathrm{HT}_{1 \mathrm{~A}}$, contributed greatly to the formation of strong hydrogen bonds and the total binding energy. Moreover, three hydrophobic residues, Val1 $17^{3.33}$, Asn365 $5^{6.55}$, and Ala383 $3^{7.35}$ (bold, Table 1), were unique in 5$\mathrm{HT}_{1 \mathrm{~A}}$, which may contribute to the selectivity via potential hydrophobic interactions. Based on our results, Met $103^{3.33}$ in 5-

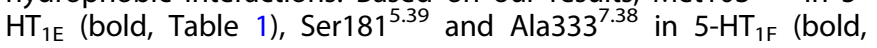
Table 1) were unique residues, and these residues may contribute to the selectivity of these two receptors. Moreover, our docking results and MD results indicate that Ser242.461 in $5-\mathrm{HT}_{2 \mathrm{~A}}$ and Met218 $1.40 /$ Glu363 3.35 in $5-\mathrm{HT}_{2 B}$ (bold, Table 1 ) could be major contributors to their selectivity. In addition, Thr104 $4^{3.36}$ (bold, Table 1 ) is highly likely to be a major contributor to the selectivity of $5-\mathrm{HT}_{4}$ due to its uniqueness and ability to form strong hydrogen bonds. Finally, Ser321 $21^{7.35}$ in 5- $\mathrm{HT}_{5}$, Thr196.461 in 5- $\mathrm{HT}_{6}$, and Arg $367^{7.35}$ in $5-\mathrm{HT}_{7}$ (bold, Table 1) were unique to each receptor and played essential roles in their binding processes.

The results from the hallucinogen knowledgebase, molecular docking study, and MD simulation performed on Captagon provide new information regarding the mechanism of Captagon. From the target prediction and interactions between Captagon and these $5-\mathrm{HT}$ receptors, our results suggest that $5-\mathrm{HT}_{2}, 5-\mathrm{HT}_{5 \mathrm{~A}}$, and $5-\mathrm{HT}_{7}$ were the most promising targets for unmetabolized Captagon. We aim to conduct additional experiments in the future to explore the interactions between Captagon and 5- $\mathrm{HT}$ receptors in more detail.

\section{CONCLUSION}

In the present work, we built 5-HT receptor subtype threedimensional models based on the published crystal structure of $5-\mathrm{HT}_{1 \mathrm{~B}} / 5-\mathrm{HT}_{2 \mathrm{~B}} / 5-\mathrm{HT}_{2 \mathrm{C}}$ through homology modeling. Based on the results of our molecular docking and MD simulation studies, we identified commonalities in uniqueness in residues that greatly contributes to the selectivity of each receptor. We hope the present work can be used to facilitate drug discovery of 5-HTrelated medications to design compounds with high selectivity for each receptor subtype to decrease undesirable events such as addiction and side effects.

\section{ACKNOWLEDGEMENTS}

The project was supported by funding from the National Natural Science Foundation of China (31400667), the Chongqing Municipal Education Commission Science and Technology Research Project (KJ1500902, KJ1600908), and the Chongqing Research Program of Basic Research and Frontier Technology (cstc2018jcyjAX0683). The authors acknowledge the funding support to the Xie laboratory from the NIH NIDA (P30 DA035778A1), NIH (R01 DA025612), and the Department of Defense (W81XWH16-1-0490), computational support from the Center for Research Computing of University of Pittsburgh, and the Extreme Science and Engineering Discovery Environment (CHE090098, MCB170099).

\section{AUTHOR CONTRIBUTIONS}

XQX and ZWF designed the study. YQW, WWL, NW, SYW, MZC, ZHL and ZWF performed the research, analyzed the data, and wrote the paper.

\section{ADDITIONAL INFORMATION}

The online version of this article (https://doi.org/10.1038/s41401-019-0217-9) contains supplementary material, which is available to authorized users.

Competing interests: $\mathrm{X}-\mathrm{QX}$ is the Founder of ID4Pharma and serves as a consultant for Oxis Biotech. The other authors declare no competing interests.

\section{REFERENCES}

1. Hannon J, Hoyer D. Molecular biology of 5-HT receptors. Behav Brain Res. 2008;195:198-213. 
2. Dorocic IP, Fürth D, Xuan Y, Johansson Y, Pozzi L, Silberberg G, et al. A wholebrain atlas of inputs to serotonergic neurons of the dorsal and median raphe nuclei. Neuron. 2014;83:663-78.

3. Francken BJ, Jurzak M, Vanhauwe JF, Luyten WH, Leysen JE. The human 5-ht5A receptor couples to Gi/Go proteins and inhibits adenylate cyclase in HEK 293 cells. Eur J Pharmacol. 1998;361:299-309.

4. Pittala V, Pittala D. Latest advances towards the discovery of 5-HT7 receptor ligands. Mini Rev Med Chem. 2011;11:1108-21.

5. Tseng K-Y, Atzori M. Monoaminergic modulation of cortical excitability. (Springer, New York, 2007).

6. Cheng J, Giguère PM, Onajole OK, Lv W, Gaisin A, Gunosewoyo H, et al. Optimization of 2-phenylcyclopropylmethylamines as selective serotonin $2 \mathrm{C}$ receptor agonists and their evaluation as potential antipsychotic agents. J Med Chem. 2015;58:1992-2002.

7. Beliveau V, Ganz M, Feng L, Ozenne B, Højgaard L, Fisher PM, et al. A highresolution in vivo atlas of the human brain's serotonin system. J Neurosci. 2017;37:120-8

8. Kim S-K, Goddard WA III. Molecular-docking-based drug design and discovery: rational drug design for the subtype selective GPCR ligands. In: Applied Case Studies and Solutions in Molecular Docking-Based Drug Design (Siavoush Dastmalchican ed.). IGI Global; 2016, p. 158-85.

9. Noda M, Higashida H, Aoki S, Wada K. Multiple signal transduction pathways mediated by 5-HT receptors. Mol Neurobiol. 2004;29:31-9.

10. Spina $E$, Trifirò $G$, Caraci $F$. Clinically significant drug interactions with newer antidepressants. CNS Drugs. 2012;26:39-67.

11. MacGregor EA, Pawsey SP, Campbell JC, Hu X. Safety and tolerability of frovatriptan in the acute treatment of migraine and prevention of menstrual migraine: results of a new analysis of data from five previously published studies. Gend Med. 2010;7:88-108.

12. Megens A, Awouters F, Schotte A, Meert T, Dugovic C, Niemegeers C, et al. Survey on the pharmacodynamics of the new antipsychotic risperidone. Psychopharmacology. 1994;114:9-23.

13. Han DD, Gu HH. Comparison of the monoamine transporters from human and mouse in their sensitivities to psychostimulant drugs. BMC Pharmacol. 2006;6:6.

14. Müller CP, Carey RJ, Huston JP, De Souza Silva MA. Serotonin and psychostimulant addiction: focus on 5-HT1A-receptors. Prog Neurobiol. 2007;81:133-78.

15. Engleman E, Rodd Z, Bell R, Murphy J. The role of $5-\mathrm{HT} 3$ receptors in drug abuse and as a target for pharmacotherapy. CNS Neurol Disord Drug Targets. 2008;7:454-67.

16. Wang $C$, Jiang $\mathrm{Y}, \mathrm{Ma} J$, Wu H, Wacker $\mathrm{D}$, Katritch $\mathrm{V}$, et al. Structural basis for molecular recognition at serotonin receptors. Science. 2013;340:610-4.

17. Wacker D, Wang C, Katritch V, Han GW, Huang X-P, Vardy E, et al. Structural features for functional selectivity at serotonin receptors. Science. 2013; 340:615-9.

18. Peng Y, McCorvy JD, Harpsøe K, Lansu K, Yuan S, Popov P, et al. 5-HT2C receptor structures reveal the structural basis of GPCR polypharmacology. Cell. 2018;172:719-30. e14

19. Eswar N, Webb B, Marti-Renom MA, Madhusudhan M, Eramian D, My Shen, et al. Comparative protein structure modeling using Modeller. Curr Protoc Bioinf. 2006;15:5.6. 1-5.6. 30

20. Pándy-Szekeres G, Munk C, Tsonkov TM, Mordalski S, Harpsøe K, Hauser AS, et al. GPCRdb in 2018: adding GPCR structure models and ligands. Nucleic Acids Res. 2017:46:D440-D6.

21. Jain AN. Scoring noncovalent protein-ligand interactions: a continuous differentiable function tuned to compute binding affinities. J Comput Aid Mol Des. 1996;10:427-40

22. Chen J-Z, Wang J, Xie X-Q. GPCR structure-based virtual screening approach for CB2 antagonist search. J Chem Inf Model. 2007;47:1626-37.

23. Feng $Z$, Alqarni $M H$, Yang $P$, Tong $Q$, Chowdhury $A$, Wang $L$, et al. Modeling, molecular dynamics simulation, and mutation validation for structure of cannabinoid receptor 2 based on known crystal structures of GPCRs. J Chem Inf Model. 2014:54:2483-99.

24. Feng Z, Kochanek S, Close D, Wang L, Srinivasan A, Almehizia AA, et al. Design and activity of AP endonuclease-1 inhibitors. J Chem Biol. 2015;8:79-93.

25. Feng Z, Pearce LV, Xu X, Yang X, Yang P, Blumberg PM, et al. Structural insight into tetrameric hTRPV1 from homology modeling, molecular docking, molecular dynamics simulation, virtual screening and bioassay validations. J Chem Inf Model. 2015;54:2483-99.

26. Maier JA, Martinez C, Kasavajhala K, Wickstrom L, Hauser KE, Simmerling C. ff14SB: improving the accuracy of protein side chain and backbone parameters from ff99SB. J Chem Theory Comput. 2015;11:3696-713.

27. Jorgensen WL, Chandrasekhar J, Madura JD, Impey RW, Klein ML. Comparison of simple potential functions for simulating liquid water. J Chem Phys. 1983;79:926-35
28. Jakalian A, Jack DB, Bayly $\mathrm{Cl}$. Fast, efficient generation of high-quality atomic charges. AM1-BCC model: II. Parameterization and validation. J Comput Chem. 2002;23:1623-41

29. Wang J, Wolf RM, Caldwell JW, Kollman PA, Case DA. Development and testing of a general amber force field. J Comput Chem. 2004;25:1157-74.

30. Götz AW, Williamson MJ, Xu D, Poole D, Le Grand S, Walker RC. Routine microsecond molecular dynamics simulations with AMBER on GPUs. 1. Generalized born. J Chem Theory Comput. 2012;8:1542-55.

31. Salomon-Ferrer R, Götz AW, Poole D, Le Grand S, Walker RC. Routine microsecond molecular dynamics simulations with AMBER on GPUs. 2. Explicit solvent particle mesh Ewald. J Chem Theory Comput. 2013;9:3878-88.

32. Case D.A., Betz R.M., Cerutti D.S., Cheatham T.E., III, Darden T.A., Duke R.E. et al. AMBER 2016, University of California, San Francisco. 2016

33. Loncharich RJ, Brooks BR, Pastor RW. Langevin dynamics of peptides: the fric tional dependence of isomerization rates of $\mathrm{N}$-acetylalanyl- $\mathrm{N}^{\prime}$-methylamide. Biopolymers. 1992;32:523-35.

34. Izaguirre JA, Catarello DP, Wozniak JM, Skeel RD. Langevin stabilization of molecular dynamics. J Chem Phys. 2001;114:2090-8.

35. Darden T, York D, Pedersen L. Particle mesh Ewald: an N. log (N) method for Ewald sums in large systems. J Chem Phys. 1993;98:10089-92.

36. Essmann U, Perera L, Berkowitz ML, Darden T, Lee H, Pedersen LG. A smooth particle mesh Ewald method. J Chem Phys. 1995;103:8577-93.

37. Ryckaert J-P, Ciccotti G, Berendsen HJ. Numerical integration of the cartesian equations of motion of a system with constraints: molecular dynamics of $n$ alkanes. J Comput Phys. 1977;23:327-41.

38. Wang J, Hou T. Develop and test a solvent accessible surface area-based model in conformational entropy calculations. J Chem Inf Model. 2012;52:1199-212.

39. Hawkins GD, Cramer CJ, Truhlar DG. Parametrized models of aqueous free energies of solvation based on pairwise descreening of solute atomic charges from a dielectric medium. J Phys Chem. 1996;100:19824-39.

40. Kollman PA, Massova I, Reyes C, Kuhn B, Huo S, Chong L, et al. Calculating structures and free energies of complex molecules: combining molecular mechanics and continuum models. Acc Chem Res. 2000;33:889-97.

41. Sun $H$, Duan $L$, Chen F, Liu H, Wang Z, Pan P, et al. Assessing the performance of MM/PBSA and MM/GBSA methods. 7. Entropy effects on the performance of endpoint binding free energy calculation approaches. Phys Chem Chem Phys. 2018;20:14450-60.

42. Chen F, Liu H, Sun H, Pan P, Li Y, Li D, et al. Assessing the performance of the MM/ PBSA and MM/GBSA methods. 6. Capability to predict protein-protein binding free energies and re-rank binding poses generated by protein-protein docking Phys Chem Chem Phys. 2016;18:22129-39.

43. Sun $H$, Li Y, Shen $M$, Tian $S, X u L$, Pan $P$, et al. Assessing the performance of $M M /$ PBSA and MM/GBSA methods. 5. Improved docking performance using high solute dielectric constant MM/GBSA and MM/PBSA rescoring. Phys Chem Chem Phys. 2014; 16:22035-45.

44. Sun $\mathrm{H}$, Li Y, Tian $\mathrm{S}$, Xu L, Hou TJPCCP. Assessing the performance of MM/PBSA and MM/GBSA methods. 4. Accuracies of MM/PBSA and MM/GBSA methodologies evaluated by various simulation protocols using PDBbind data set. Phys Chem Chem Phys. 2014;16:16719-29.

45. Tsui V, Case DA. Theory and applications of the generalized born solvation model in macromolecular simulations. Biopolymers . 2000;56:275-91.

46. Bashford D, Case DA. Generalized born models of macromolecular solvation effects. Annu Rev Phys Chem. 2000;51:129-52.

47. Sitkoff D, Sharp KA, Honig B. Accurate calculation of hydration free energies using macroscopic solvent models. J Phys Chem. 1994;98:1978-88.

48. Still WC, Tempczyk A, Hawley RC, Hendrickson T. Semianalytical treatment of solvation for molecular mechanics and dynamics. J Am Chem Soc. 1990; 112:6127-9.

49. Weiser J, Shenkin PS, Still WC. Approximate atomic surfaces from linear combinations of pairwise overlaps (LCPO). J Comput Chem. 1999;20:217-30.

50. Hu J, Feng Z, Ma S, Zhang Y, Tong Q, Alqarni MH, et al. Difference and influence of inactive and active states of cannabinoid receptor subtype CB2: from conformation to drug discovery. J Chem Inf Model. 2016;56:1152-63.

51. Xu X, Ma S, Feng Z, Hu G, Wang L, Xie X-QJJoMG, et al. Chemogenomics knowledgebase and systems pharmacology for hallucinogen target identification —-salvinorin A as a case study. J Mol Graph Model. 2016;70:284-95.

52. Wang L, Ma C, Wipf P, Liu H, Su W, Xie X-QJTAj. TargetHunter: an in silico target identification tool for predicting therapeutic potential of small organic molecules based on chemogenomic database. AAPS J. 2013;15:395-406.

53. Liu H, Wang L, Lv M, Pei R, Li P, Pei Z, et al. AlzPlatform: an Alzheimer's disease domain-specific chemogenomics knowledgebase for polypharmacology and target identification research. J Chem Inf Model. 2014;54:1050-60.

54. Xue Y, Feng Z-w, Li X-y, Hu Z-h, Xu Q, Wang Z, et al. The efficacy and safety of cilostazol as an alternative to aspirin in Chinese patients with aspirin intolerance 
after coronary stent implantation: a combined clinical study and computational system pharmacology analysis. Acta Pharmacol Sin. 2018;39:205.

55. Zhang H, Ma S, Feng Z, Wang D, Li C, Cao Y, et al. Cardiovascular disease chemogenomics knowledgebase-guided target identification and drug synergy mechanism study of an herbal formula. Sci Rep. 2016;6:33963.

56. Shannon P, Markiel A, Ozier O, Baliga NS, Wang JT, Ramage D, et al. Cytoscape: a software environment for integrated models of biomolecular interaction networks. Genome Res. 2003;13:2498-504.

57. Johansson L, Sohn D, Thorberg SO, Jackson DM, Kelder D, Larsson LG, et al. The pharmacological characterization of a novel selective 5-hydroxytryptamine $(1 \mathrm{~A})$ receptor antagonist, NAD-299. J Pharmacol Exp Ther. 1997;283:216-25.

58. Middlemiss DN, Gothert M, Schlicker E, Scott CM, Selkirk JV, Watson J, et al. SB236057, a selective 5-HT1B receptor inverse agonist, blocks the 5-HT human terminal autoreceptor. Eur J Pharmacol. 1999;375:359-65.

59. Schmitz B, Ullmer C, Segelcke D, Gwarek M, Zhu XR, Lubbert H. BF-1-A novel selective $5-\mathrm{HT} 2 \mathrm{~B}$ receptor antagonist blocking neurogenic dural plasma protein extravasation in guinea pigs. Eur J Pharmacol. 2015;751:73-80.

60. Kennett GA, Wood MD, Bright F, Trail B, Riley G, Holland V, et al. SB 242084, a selective and brain penetrant $5-\mathrm{HT} 2 \mathrm{C}$ receptor antagonist. Neuropharmacology. 1997;36:609-20.

61. Sleight AJ, Boess FG, Bos M, Levet-Trafit B, Riemer C, Bourson A. Characterization of Ro 04-6790 and Ro 63-0563: potent and selective antagonists at human and rat 5-HT6 receptors. Br J Pharmacol. 1998;124:556-62.

62. Forbes IT, Douglas S, Gribble AD, Ife RJ, Lightfoot AP, Garner AE, et al. SB-656104A: a novel 5-HT7 receptor antagonist with improved in vivo properties. Bioorg Med Chem Lett. 2002;12:3341-4.
63. Alabdalla MA. Chemical characterization of counterfeit captagon tablets seized in Jordan. Forensic Sci Int. 2005;152:185-8.

64. Al-Hemiary NJ, Al-Diwan JK, Hasson AL, Rawson RA. Drug and alcohol use in Iraq: findings of the inaugural Iraqi Community Epidemiological Workgroup. Subst Use Misuse. 2014;49:1759-63.

65. Katselou M, Papoutsis I, Nikolaou P, Qammaz S, Spiliopoulou C, Athanaselis S. Fenethylline (Captagon) abuse-local problems from an old drug become universal. Basic. Clin Pharmacol. 2016;119:133-40.

66. Kristen G, Schaefer A, Von Schlichtegroll A. Fenetylline: therapeutic use, misuse and/or abuse. Drug Alcohol Depen. 1986;17:259-71.

67. Van Hout MC, Wells J. Is Captagon (fenethylline) helping to fuel the Syrian conflict? Addiction. 2016;111:748-9.

68. Wenthur CJ, Zhou B, Janda KD. Vaccine-driven pharmacodynamic dissection and mitigation of fenethylline psychoactivity. Nature. 2017;548:476-9.

69. Ma C, Wang L, Xie X-Q. Ligand classifier of adaptively boosting ensemble decision stumps (LiCABEDS) and its application on modeling ligand functionality for $5 \mathrm{HT}$ subtype GPCR families. J Chem Inf Model. 2011:51:521-31.

70. Ma C, Wang L, Yang P, Myint KZ, Xie X-Q. LiCABEDS II. Modeling of ligand selectivity for G-protein-coupled cannabinoid receptors. J Chem Inf Model. 2013;53:11-26.

71. Zhao $\mathrm{YH}$, Abraham $\mathrm{MH}$, Ibrahim A, Fish PV, Cole $\mathrm{S}$, Lewis $\mathrm{ML}$, et al. Predicting penetration across the blood-brain barrier from simple descriptors and fragmentation schemes. J Chem Inf Model. 2007;47:170-5.

72. Nickel B, Niebch G, Peter G, Von Schlichtegroll A, Tibes U. Fenetylline: new results on pharmacology, metabolism and kinetics. Drug Alcohol Depend. 1986;17:235-57. 